ISSN: 0213-2060

DOI: https://doi.org/10.14201/shhme2019372528

\title{
LA VIOLENCIA DEL CORNUDO COMO REACCIÓN ANTE EL DELITO DE ADULTERIO. UN ESTUDIO INTERDISCIPLINAR DE LA REGULACIÓN CASTELLANOLEONESA DEL SIGLO XIII ${ }^{1}$
}

\author{
The Violence of the Cuckold as a Reaction to the Crime of Adultery. An Interdisciplinary \\ Study of the Castilian-Leonese Regulation from the $13^{\text {th }}$ Century \\ Plácido FERNÁNDEZ-VIAGAS ESCUDERO \\ Depto. de Historia Medieval y Ciencias y Técnicas Historiográficas. Facultad de Geografia e Historia. Universidad \\ de Sevilla. C/ Doña María de Padilla, s/n. E-41004 SEVILLA. C. e.: placidofve@gmail.com
}

Recibido: 2018-04-11

Revisado: 2019-04-08

Aceptado: 2019-11-08

RESUMEN: El adulterio femenino y la venganza privada como reacción al mismo fueron cuestiones reguladas frecuentemente en las leyes castellanoleonesas del siglo XIII, bajo diferentes formulaciones jurídicas. Nuestro objetivo será sumergirnos en este panorama con una lógica interdisciplinar, que nos permitirá realizar un estudio de la práctica legislativa a la luz del marco cultural y simbólico al que pertenece.

Palabras clave: Fueros; Castilla; Venganza privada; Ius occidendi; Adulterio.

ABSTRACT: Female adultery and private revenge as a reaction to that crime were issues often regulated in Castilian and Leonese laws from the $13^{\text {th }}$ Century, under very different legal formulations. Our goal is to interpret this juridical framework in an interdisciplinary way, in order to explain these laws under their cultural and symbolic context.

Keywords: Fueros; Castile; Private Revenge; Ius occidendi; Adultery.

1 Abreviaturas empleadas: C. = Códice; Calila = Calila e Dimna; CEM. = Cantigas de escarnio y maldecir; CM. = Chronicon Mundi; Dig. = Digesto; F. = Fuero; f. = folio; GE. = General Estoria de Alfonso X; L. = Liber; PCG. = Primera Crónica General; V. = Viejo.

Las fuentes empleadas en el presente trabajo serán citadas de forma abreviada en las diferentes notas al pie. No obstante, las ediciones de todas las fuentes serán recogidas en forma desarrollada en el apartado de Fuentes empleadas.

Agradezco al profesor catedrático Luis Miguel Ribeiro de Oliveira Duarte, de la Facultad de Letras de Oporto, por facilitarme la consulta de las fuentes portuguesas recogidas en el presente artículo durante mi estancia de investigación de cuatro meses en dicho centro universitario en el año 2017. 
LA VIOLENCIA DEL CORNUDO COMO REACCIÓN ANTE EL DELITO DE ADULTERIO. UN ESTUDIO INTERDISCIPLINAR DE LA REGULACIÓN CASTELLANOLEONESA DEL SIGLO XIII PLÁCIDO FERNÁNDEZ-VIAGAS ESCUDERO

SUMARIO: 0 Introducción. 1 La venganza privada del marido ante el adulterio en los fueros municipales castellanoleoneses del siglo XIII previos a las Partidas. 2 La venganza privada del marido ante el adulterio en las Partidas. 3 Conclusiones. 4 Fuentes empleadas. 5 Referencias bibliográficas.

\section{$0 \quad$ INTRODUCCIÓN}

En las normas que aborda nuestro estudio encontramos diferentes leyes penales que protegían, principalmente, tanto el bien jurídico del honor familiar como el honor del hombre en relación con la conducta sexual de su mujer ${ }^{2}$. En el apartado segundo abordaremos pormenorizadamente el supuesto principal, que lo constituye el delito de adulterio, y que era regulado por una vasta colección de fueros y de cuerpos legales. Pero conviene comentar otras diversas actuaciones que agredían al honor del varón, entre otros bienes dignos de protección, y que la legislación de la época configuraba penalmente para reconstruir un contexto normativo más amplio en el que insertar nuestra interpretación.

En primer lugar tenemos el denuesto de cornudo (o sus sinónimos), que aparece muy frecuentemente recogido en la redacción del delito de injurias o denuestos en la legislación de la época, tanto en los fueros castellanoleoneses de la familia de Cuenca-Teruel ${ }^{3}$, como en la de Coria-Cima-Côa ${ }^{4}$, en la de Sahagún ${ }^{5}$ y en la de León ${ }^{6}$, así como en varios otros $^{7}$. Esta reiteración del vocablo en los fueros nos descubre su vigencia social, así como

2 Respecto del contenido que le damos al vocablo honor en el presente estudio, compartimos la definición propuesta por J. Pitt-Rivers, que le otorga un ámbito privado, referido a la estima propia, y uno externo o público, propio de la opinión ajena (cf. PitT-Rivers, Julien. "Honor y categoría social». En Peristiany, John G. El concepto del honor en la sociedad mediterránea. Barcelona: Labor, 1968, p. 22; Antropología del honor o politica de los sexos. La influencia del honor y el sexo en la vida de los pueblos mediterráneos. Barcelona: Editorial Crítica, 1979, p. 18; y «La enfermedad del honor». En Gautheron, Marie (ed.). El honor. Imagen de sí mismo o don de sí, un ideal equívoco. Madrid: Cátedra, 1992, p. 235). Y entendemos que este delito afectaba directamente a ambas esferas, como nos confirma la literatura de la época.

Por otra parte, para una primera aproximación al honor del varón en relación con la conducta sexual de su mujer en el entramado jurídico y cultural del siglo XIII, véase Fernández-Viagas Escudero, Plácido. «La honra del marido como bien jurídico protegido en el delito de adulterio. Un estudio de las Partidas a la luz de sus antecedentes normativos y de su contexto legal». Clío \& Crimen, 2016, vol. 13, pp. 53-74, donde ya abordamos en profundidad algunos asuntos aquí mencionados y otros relacionados, y donde mencionamos otros bienes o valores jurídicos dańados por el adulterio.

3 Cf. F. Cuenca 306 (12.3), C. Valentino 2.2.2, F. Béjar 356, F. Zorita, 274, F. Úbeda 30,1, F. Iznatoraf 275, F. Sabiote 277, F. Andújar 263, F. Huete 260, F. Alcaraz 4.55, F. Alarcón 261, F. Alcázar 261 y F. Brihuega 92. Como puede comprobarse, no mencionamos los fueros posteriores al siglo XIII de esta familia, y lo mismo ocurrirá con el resto de las familias forales.

4 Cf. F. Coria 183, F. Cáceres 186, F. Usagre 189, F. Castel-Rodrigo 3.51, F. Alfaiates 184, F. CastelMelhor 122 y F. CasteloBom 188.

5 Cf. F. Allariz 23, F. Avilés 15, F. Ribadavia 37, F. Oviedo 15 y F. Bonoburgo 31.

6 Cf. F. León 13, F. Milmanda 26, F. Llanes 13 y F. Parga 14.

7 Cf. F. Lara 14, F. Alhóndiga 12, F. Molina 20.1, F. Medinaceli 27, F. Ledesma 184, F. Guadalajara 115, F. Uclés 45 y 185, F. Alcalá de Henares 111, F. Real 4.3.2, F.V. Castilla 2.1.9, así como F. Fijosdalgo 73.

Sobre este denuesto en la legislación castellana, véanse también los trabajos de SERra Ruiz, Rafael. Honor, honra e injuria en el derecho medieval español. Murcia: Sucesores de Nogués, 1969; Pérez Martín, Antonio. 
la identidad deteriorada del cornudo ante el resto, que interpretamos como el reflejo de la contaminación simbólica que se generaba tras adulterio sobre el ofendido en el campo social ${ }^{8}$. Esta condición del cornudo es confirmada por la literatura no jurídica de la época, particularmente por las llamadas cantigas de escarnio y maldecir gallegoportuguesas, que tienen en el adulterio de la mujer uno de sus temas recurrentes y que, generalmente, retratan como seres pusilánimes a los varones afectados por dichas prácticas $^{9}$. Pero, junto con estas injurias de palabra, tenemos la injuria de hecho consistente en arrojar huesos o cuernos en casa ajena, que encontramos configurada penalmente en los fueros de la época y que atentaba contra el honor del hombre, anunciando una conducta sexual desviada por parte de su mujer ${ }^{10}$. Finalmente, hallamos el delito consistente en alabarse de mujer ajena, que era castigado con el pago de una calońa principalmente en los fueros de la familia de Cuenca-Teruel ${ }^{11}$ y que provocaba un daño al honor del marido equiparable al de los anteriores supuestos. Por lo tanto, las normas que protegían el honor del hombre ante ataques relacionados con la conducta sexual femenina no se limitaban a las contenidas en la regulación del delito de adulterio. Sin embargo, en nuestro estudio, aunque no perdamos de vista las anteriores normas, nos centraremos en estas últimas, y particularmente abordaremos la cuestión de la reacción violenta como respuesta ante el ilícito, tanto en su dimensión jurídica como cultural y social.

Respecto de la dimensión jurídica, J. M. a García Marín considera como un supuesto de legítima defensa del honor la venganza privada ejercida ante el adulterio flagrante de la mujer en las normas del período que comprende nuestro estudio ${ }^{12}$. En este punto, el

«La protección del honor y de la fama en el derecho histórico español». Anales de Derecho, 1991, vol. XI, pp. 117-156; y Castillo LluCh, Mónica. «De verbo vedado: consideraciones lingüísticas sobre la agresión verbal y su expresión en castellano medieval». Cahiers de Linguistique et de Civilisation Hispaniques Médiévales, 2004, vol. 27, pp. 23-36. Para un estudio más amplio respecto de la vinculación entre el honor masculino y la actitud que se atribuye a la mujer, en el contexto de la época, cf. MADERo, Marta. Manos violentas, palabras vedadas: la injuria en Castilla y León (siglos XIII-XV). Madrid: Taurus, 1992.

8 Respecto de la impureza generada tras el adulterio y su alcance, véase la concepción del mismo y su transcendencia en PitT-Rivers, "La enfermedad del honor», p. 241, o, desde una aproximación teórica diferente, en Douglas, Mary. Pureza y peligro. Madrid: Siglo XXI Editores, 1973.

9 Sin ánimo de agotar la casuística, cf. CEM 76, 106, 182, 185, 210, 212, 227, 269, 296, 353, 355 , $360,361,369,412,414$ y, probablemente, también en la cantiga 312 exista un trasfondo relacionado con esta cuestión. Para la numeración de las cantigas empleamos el trabajo compilador de M. Rodríguez Lapa citado en el apartado último de fuentes. Véase la completa identificación de todas estas cantigas de escarnio que, en opinión de Maria da Graça Videira Lopes, trataban el tema del adulterio en Lopes, Maria da Graça Videira. A sátira nos cancioneiros medievais galego-portugueses. Lisboa: Estampa, 1994, 2. ${ }^{\text {a ed., p. }} 376$.

Atribuido por estas piezas literarias al marido cornudo, véase el trabajo de JimÉnez CabANEs, Pilar. «El deseo femenino a la luz de algunas composiciones literarias medievales». Lemir, 2005, vol. 9, s. p.

10 En cuanto a los fueros castellanos de la familia de Cuenca-Teruel, cf. F. Cuenca 163 (6.15), F. Béjar 160, F. Zorita 127, F. Úbeda 15.6, F. Iznatoraf 132, F. Sabiote 133, F. Andújar 122, F. Huete 104, F. Alcaraz 3.16, F. Plasencia 117, F. Alarcón 129, F. Alcázar 129 y F. Sepúlveda 162.

Pero este delito no solo fue regulado en los fueros municipales, sino también en las Partidas, como puede comprobarse en la ley vi, del título IX, del libro viI.

11 Cf. F. Cuenca 348 (13.8), C. Valentino 2.3.8, F. Béjar 403, F. Zorita, 314, F. Úbeda 31, pr, F. Iznatoraf 320, F. Sabiote 277, F. Andújar 294, F. Huete 267, F. Alcaraz 4.95, F. Alarcón 299 y F. Brihuega 136.

12 Cf. García Marín, José María. «La legítima defensa hasta fines de la Edad Media. Notas para su estudio». Anuario de Historia del Derecho Español, 1987, vol. 57, p. 413-438. 
LA VIOLENCIA DEL CORNUDO COMO REACCIÓN ANTE EL DELITO DE ADULTERIO. UN ESTUDIO INTERDISCIPLINAR DE LA REGULACIÓN CASTELLANOLEONESA DEL SIGLO XIII PLÁCIDO FERNÁNDEZ-VIAGAS ESCUDERO

análisis jurídico coincide esencialmente con el de carácter antropológico, que interpreta la explosión violenta contra los ofensores como una acción con una fuerza simbólica apropiada para reivindicar el honor comprometido ${ }^{13}$. Bajo un enfoque sociológico más profundo, y específicamente en cuanto al homicidio ejecutado por el cornudo (ya sea en caso de flagrante delito o no), cabe interpretar el mismo no solo como un medio para reivindicar su honor, sino como el vehículo adecuado para frenar la contaminación simbólica desatada tras el adulterio y para mantenerse al margen de la impureza ${ }^{14}$, demostrando con dicha violencia el carácter y la virilidad comprometidos por la infidelidad sexual femenina ${ }^{15}$. En ese contexto, el marido homicida no solo reivindica su honor comprometido con el adulterio, sino que demuestra ante los demás una virilidad que lo aleja de toda contaminación simbólica tras el adulterio y de la separación ritual consiguiente, que bien podía materializarse mediante una exclusión verbal ante la comunidad, consistente en burlas o denuestos, como nos ponen de manifiesto las cantigas de escarnio y maldecir de la época y la frecuencia con la que aparece el insulto de cornudo en los fueros.

En consecuencia nuestra aproximación al objeto de estudio no es solo jurídica, sino que también aprovecha las aportaciones de otras ciencias sociales, como la antropología y la sociología, lo que nos conducirá por un camino interdisciplinar que consideramos el adecuado para abordar la categoría del honor en el contexto medieval castellanoleonés. De esta manera, abordaremos la sexualidad extramatrimonial como un detonador de

13 Cf. Pitt-Rivers, «Honor y categoría social», p. 29. Sobre este particular, véase también el estudio de Jesús Ángel Solórzano Telechea, que interpreta la reacción homicida del ofendido ante el delito de adulterio como un vehículo para lavar la mancha del deshonor provocada (cf. "Justicia y ejercicio del poder: la infamia y los delitos de lujuria en la cultura legal de la Castilla medieval». Cuadernos de Historia del Derecho, 2005, vol. 12, p. 323).

14 Con carácter genérico, respecto del fenómeno de la impureza, existen diversos estudios realizados desde la sociología o bien la antropología que pueden servir de punto de apoyo en la investigación de historia cultural. Sin embargo, baste aquí mencionar los siguientes trabajos, ya clásicos, que abordan el fenómeno de la impureza desde diferentes enfoques teóricos y que analizan la sexualidad bajo los parámetros del contagio simbólico y de la exclusión social del ser contagiado: Durkheim, Émilie. Las formas elementales de la vida religiosa. Buenos Aires: Shapire, 1968; Caillois, Roger. El hombre y lo sagrado. México: Fondo de Cultura Económica, 1984; y VAN DER Leeuw, Gerardus. La fenomenología de la religión. México-Buenos Aires: Fondo de Cultura Económica, 1964; como también resulta de interés consultar la obra de Douglas, Pureza y peligro y la de Girard, René. La violencia y lo sagrado. Barcelona: Anagrama, 1972, pp. 14, 76, 170, 177-187 y 189 190, para analizar la cuestión de la contaminación devenida por el adulterio y la fuerza que puede desatarse en respuesta. Por último, nótese que, en materia de derecho medieval castellano, esta concepción de la sexualidad como posible fuente de impureza, con la consiguiente necesidad de separación del ser impuro, parece aplicarse para el estudio de las agresiones sexuales en los fueros castellanos en Heusch, Carlos. «Femmes et violences dans les fueros castillans du Moyen Âge». Cahiers d'Études Hispaniques Médiévales, 2005, vol. 28, pp. $307-$ 339, si bien de una manera más intuitiva que científica.

15 Esta visión ya tuvimos ocasión de presentarla en FERnÁndeZ-VIAGAS EsCUdERO, «La honra del marido». En este punto, en opinión de J. Pitt-Rivers, téngase en cuenta que la contaminación ritual que padece el marido con el adulterio uxorio como telón de fondo se explica en las sociedades tradicionales mediterráneas por su falta de carácter, demostrada al no controlar la fidelidad sexual de su mujer, que lo presenta como un ser poco viril ante el resto. Sobre este tema y sobre la falta de virilidad atribuida al cornudo según las creencias populares, cf. PitT-Rivers, «La enfermedad del honor», p. 241. Por otra parte, respecto de la visión de los maridos engańados como hombres poco viriles en la literatura peninsular del siglo XIII, especialmente en las cantigas de escarnio y maldecir, cf. nota 8 y Jiménez Cabanes, «El deseo femenino». 
impureza y, por tanto, de degradación y exclusión social, que particularmente perjudicaba al varón ofendido por el adulterio uxorio, en los términos previamente expresados. En esta tarea de historia cultural, en la que hemos de emplear diversas fuentes, no solo jurídicas, nos inspiraremos en una técnica propia de la etnografía, pero que exitosamente ha sido empleada en diversos campos de las ciencias sociales, llamada descripción densa ${ }^{16}$, para comprender las normas objeto de nuestro análisis en toda su dimensión, dentro del complejo entramado simbólico de la época ${ }^{17}$.

Por último, téngase en cuenta que en la nota 60 de un reciente artículo sobre las leyes Ix, del título xxIv, y x, del título xxv, de la Séptima Partida ${ }^{18}$, que regulaban las relaciones sexuales entre cristianas y miembros de minorías religiosas, trazamos una explicación esquemática respecto de la cuestión de la venganza privada en caso de adulterio en el derecho medieval castellanoleonés. Sirva este trabajo para presentar una panorámica completa sobre el asunto, para realizar reflexiones de fondo y en detalle y para tratar diversos asuntos íntimamente relacionados.

\section{LA VENGANZA PRIVADA DEL MARIDO ANTE EL ADULTERIO EN LOS FUEROS MUNICIPALES Castellanoleoneses del siglo XIII previos a las Partidas}

En la producción literaria castellanoleonesa del siglo XIII encontramos diversas formas de expresión de esta violencia privada como respuesta al adulterio uxorio. Específicamente, en lo que requiere de nuestro principal interés, nótese que este topus literario se hallaba frecuentemente en la literatura jurídica del período. De esta manera, en el entramado cultural castellanoleonés la venganza privada ejecutada por el desposado o el marido en caso de adulterio era una reacción amparada legalmente en una gran diversidad de fueros, enormemente influidos en su mayoría por el Liber Iudiciorum, mientras que no era contemplada como una respuesta inmoral en la literatura no jurídica de la época ${ }^{19}$. En materia jurídica, abordaremos en primer lugar cómo se encontraba regulada la cuestión en la familia de fueros de Cuenca-Teruel, no por una razón de orden

16 Respecto de esta herramienta interpretativa, cf. Geertz, Clifford. La interpretación de las culturas. Barcelona: Gedisa, 2003.

17 Esta técnica interpretativa también inspiró la aproximación al objeto de estudio en varios otros de nuestros artículos, como puede comprobarse en Fernández-Viagas Escudero, "La honra del marido»; «El rey en las Partidas de Alfonso X: su Vicariato Divino y su caracterización bajo esquemas de sacralidad». Hispania Sacra, 2017, vol. 139, pp. 61-80; "Las relaciones sexuales entre miembros de minorías religiosas y mujeres cristianas en la Séptima Partida. Un estudio interdisciplinar de las leyes 7.24.9 y 7.25.10». En la España Medieval, 2017, vol. 40, pp. 269-308; y «De los alcahuetes. Un estudio del título xxir de la Séptima Partida». Cuadernos de Historia del Derecho, 2017, vol. 24, pp. 219-242.

18 FERnÁndez-Viagas Escudero, «Las relaciones sexuales».

19 A este respecto, con sus diferencias, véanse tanto casos de reacción violenta del marido contra el amante adúltero en diferentes textos (cf. PCG 172 y Calila pp. 139-140 [téngase en cuenta que en esta fuente citamos directamente las páginas de la edición que manejamos, ante la ausencia de una numeración más precisa en capítulos o parágrafos del texto original]), como contra su propia mujer, sobre la que recaían sospechas de adulterio (cf. CM. 1.5.40 y Calila pp. 273-279), bajo la completa ausencia de reproche moral respecto del marido que así actuaba. 
LA VIOLENCIA DEL CORNUDO COMO REACCIÓN ANTE EL DELITO DE ADULTERIO. UN ESTUDIO INTERDISCIPLINAR DE LA REGULACIÓN CASTELLANOLEONESA DEL SIGLO XIII PLÁCIDO FERNÁNDEZ-VIAGAS ESCUDERO

cronológico $^{20}$, sino por tener mayor extensión territorial y poseer mayor influencia en el territorio castellanoleonés que la familia de Coria-Cima-Côa, y a partir de ahí tendremos un punto de referencia para nuestro análisis, que continuará con el resto de los fueros municipales, transitando por el siguiente esquema central: familia de Cuenca - familia de Coria - Fuero Juzgo - Fuero Real. Para ello, utilizaremos en primer lugar el fuero de Cuenca como modelo y ańadiremos las variaciones sustanciales encontradas en otros fueros de su familia.

De esta manera, podremos comprobar cómo el ius occidendi reconocido por esta familia foral requería el ejercicio de la venganza sobre ambos delincuentes, por influencia del Liber Iudiciorum ${ }^{21}$. Esta solución fáctica amparada legalmente, y de consecuencias simbólicas previamente analizadas, es la que, en opinión de J. López Ortiz, constituye un procedimiento especial que permitía el ejercicio de la venganza en caliente, sin la declaración previa que la legitimase por autoridad judicial alguna ${ }^{22}$, por lo que apreciamos diferencias sustanciales respecto de lo dispuesto posteriormente en el fuero de Alcalá de Henares $^{23}$. Para apreciar los términos precisos de la norma conquense, baste contemplar

20 Respecto de la cronología de los diversos fueros municipales y la extensión de las familias de fueros, empleamos como referente el trabajo de Barrero García, Ana María y Alonso Martín, María Luz. Textos de derecho local español. Madrid: Consejo Superior de Investigaciones Científicas, 1989.

21 Cf. F. Iudiciorum 3.4.4, que constituye el antecedente legislativo más claro al respecto para el derecho de esta familia, si bien este código no mencionaba la circunstancia de que el amante pudiera sobrevivir al ejercicio del ius occidendi, como sí encontramos en la familia de Cuenca-Teruel. Sobre las pervivencias normativas del Liber Iudiciorum en el fuero de Cuenca, especialmente en materia de adulterio, véanse los trabajos de Alvarado Planas, Javier. "La influencia germánica en el fuero de Cuenca. La venganza de la sangre». Iacobus, 2003, vols. 15-16, pp. 55-74 y «Lobos, enemigos y excomulgados: la venganza de la sangre en el derecho medieval». En Serna Vallejo, Margarita y Baró Pazos, Juan (coords.). El fuero de Laredo en el octavo centenario de su concesión. Laredo: Universidad de Cantabria, 2001, pp. 335-366.

22 Cf. López Ortiz, José. «El proceso en los reinos cristianos de nuestra Reconquista antes de la recepción romano-canónica». Anuario de Historia del Derecho Español, 1943, vol. 14, pp. 221 y ss. Sobre estos procedimientos in fraganti, véanse también los trabajos de Hinojosa, Eduardo de. El elemento germánico en el derecho español. Madrid: Centro de Estudios Históricos, 1915, pp. 58-60; Orlandis Rovira, José. «Las consecuencias del delito en el derecho de la Alta Edad Media». Anuario de Historia del Derecho Español, 1947, vol. 18, p. 78-81; García de Valdeavellano, Luis. «El “apellido”. Notas sobre el procedimiento infraganti en el derecho español medieval». Cuadernos de Historia de España, 1947, vol. 7, pp. 67-105; García Marín, «La legítima defensa», p. 425 y ss.; y Alcalá-Zamora y Castillo, Nicolás. «Instituciones judiciales y procesales del fuero de Cuenca». Anuario de Estudios Medievales, 1982, vol. 12, pp. 67-71, entre otros. Por otra parte, para una visión general sobre el procedimiento ordinario para el ejercicio de la venganza privada en el derecho foral castellano, consistente en la declaración de enemistad previa por la autoridad jurisdiccional y la ejecución en frío de la violencia, véanse los trabajos de Hinojosa, El elemento germánico, pp. 32-69; ORLANDis Rovira, «Las consecuencias», pp. 58-65 y 110-124; Gilbert, Rafael. «Derecho penal». En Los fueros de Sepúlveda. Segovia: Diputación de Segovia, 1953, pp. 505-506; Jiménez de Asúa, Luis. Tratado de derecho penal I. Buenos Aires: Editorial Losada, 1964, pp. 710-712; y Alvarado Planas, "La influencia germánica».

23 Este fuero, si bien recibió indudables influencias del derecho de la familia de Cuenca-Teruel, no lo insertamos propiamente en ninguna de las familias de fueros del territorio castellanoleonés, siguiendo a Barrero García y Alonso Martín, Textos de derecho, pp. 101-102. Hecha esta apreciación sobre la filiación del fuero, en el mismo podemos leer lo siguiente respecto del delito de adulterio: «Todo mulier que marido oviere a bendiciones hi aleph le ficiere con otro ome e provado fuere con tres sos parientes dela, si la matare so marido, non peche los cotos ni esca enemigo» (F. Alcalá de Henares 70). Por lo tanto, y más allá de las novedades en materia de derecho procesal y en otras parcelas, el mismo concedía el ius occidendi al marido sobre 
LA VIOLENCIA DEL CORNUDO COMO REACCIÓN ANTE EL DELITO DE ADULTERIO. UN ESTUDIO INTERDISCIPLINAR DE LA REGULACIÓN CASTELLANOLEONESA DEL SIGLO XIII PLÁCIDO FERNÁNDEZ-VIAGAS ESCUDERO

la literalidad de la ley XxxviII del capítulo xi de la forma sistemática del fuero de Cuenca, que amparaba la venganza privada del marido en caso flagrante de adulterio si se mataba o pretendía matar a ambos:

Quicumque uxorem suam cum aliquo adulterantem inuenerit, et eam occiderit, non pectet calumpniam, nec exeat inimicus. Similiter si adulterum occiderit, aut ipse adulter unlneratus euaserit. Si aliter eam occiderit, pectet calumpnias, et exeat inimicus. Similiter si adulterum occiderit aut unlnerauerit, et uxorem non, utique calumpnias ${ }^{24}$.

A este respecto, véase cómo esta norma no exigía la circunstancia de la nocturnidad para amparar la venganza homicida del marido ofendido, como sí podemos encontrarla fuera del territorio castellanoleonés en el derecho de la familia del fuero de Jaca ${ }^{25}$. Por otra parte, tampoco se exigía la circunstancia de que el adulterio hubiera mancillado el hogar conyugal. En consecuencia, las únicas exigencias eran cuatro, a saber, la de la

su mujer culpable del delito, pero, en este caso, y a diferencia de los fueros de la familia de Cuenca-Teruel, no sobre el amante, lo que constituye un supuesto excepcional en el derecho municipal castellanoleonés y sin precedente en el Liber Iudiciorum. No obstante, como también podemos apreciar, sí se mantuvo de la familia de Cuenca-Teruel la condena para el marido que se extralimitase en el ejercicio de su ius occidendi.

24 Dentro de los fueros castellanoleoneses de esta familia, encontramos también esta ley en C. Valentino 2.1.23, F. Béjar 322, F. Zorita 252, F. Úbeda 28.1, F. Iznatoraf 250, F. Sabiote 251, F. Andújar 240, F. Huete 209, F. Alcaraz 4.28, F. Alarcón 236 F. Alcázar 236 y F. Plasencia 68. Por su parte, en el fuero de Sepúlveda hallamos, además de precisiones procesales novedosas respecto de las anteriores normas, la necesidad de dar muerte conjuntamente a los adúlteros sorprendidos en flagrante delito por el marido, pero sin que se contemplase, dentro de esta circunstancia eximente, el hecho de que alguno pudiere escapar herido de la reacción violenta (cf. F. Sepúlveda 73). Fuera de nuestro ámbito territorial, pero dentro de la familia de Cuenca-Teruel, el ius occidendi del marido en caso de delito flagrante era regulado en F. Teruel 368 y en F. Albarracín f. 74v (téngase en cuenta que en esta fuente citamos directamente el folio del documento original, contenido en la edición que manejamos, ante la ausencia de numeración de las leyes en el mismo).

Por otra parte, dentro de esta familia de fueros, hallamos una remisión a esta norma sobre la necesidad de aplicar la venganza sobre ambos adúlteros en la regulación del delito de adulterio cometido contra el señor, lo que se contempla tanto en el fuero de Cuenca, como en diversos otros fueros de su familia que reproducen esta norma. Respecto de lo dispuesto en el fuero de Cuenca, en su versión romanceada:

Si el mançebo asoldadado o el pastor o el boyarizo o el ortelano, a su sennor pusiere los cuernos, matelo con la mujer, commo fuero es; o lo mate publicamente, commo fuero es et lo pudiere prouar con testigos; e si lo non pudiere prouar, acuse los de traycion et rresponda a rriepto; si vençido fuere, sea en juyzio del sennor que faga del lo que quisyere; et si vençiere, que sea creydo et en canpo derreptado e sobre esto el sennor dele la soldada que le ouiere seruido (C. Valentino 4.7.2. Véase también la regulación de este delito dentro de esta familia en F. Cuenca 901 (38.2), F. Zorita 774, F. Úbeda 65, F. Iznatoraf 803, F. Sabiote 803, F. Andújar 608, F. Huete 641, F. Alcaraz 11.99, F. Alarcón 743 F. Alcázar 743 y F. Plasencia 750).

Por lo tanto, esta ley también se remitía a la pena pública para ambos delincuentes luego del oportuno proceso, contemplada en C. Valentino 2.1.20, y, asimismo, y como novedad, en caso de no poder probar con testigos su acusación, el fuero legitimaba una venganza privada del señor sobre los amantes en caso de ganar el riepto (solo se mencionaba al varón como objeto de la venganza en este supuesto, pero entendemos que, como en el caso de la aplicación de la pena pública tras el éxito de la prueba testifical, el castigo sobre la mujer debía sobreentenderse), parecida a la establecida en el Liber Iudiciorum, respecto de la venganza privada tras el oportuno proceso.

25 Cf. F. Estella 51. 
LA VIOLENCIA DEL CORNUDO COMO REACCIÓN ANTE EL DELITO DE ADULTERIO. UN ESTUDIO INTERDISCIPLINAR DE LA REGULACIÓN CASTELLANOLEONESA DEL SIGLO XIII PLÁCIDO FERNÁNDEZ-VIAGAS ESCUDERO

flagrancia del delito ${ }^{26}$, la de que el marido personalmente descubriese el delito y aplicase la venganza, la inmediatez de la misma, así como que esta se ejerciera o se hubiera pretendido ejercer sobre ambos delincuentes ${ }^{27}$, en los términos antes recogidos. De no concurrir estos cuatro requisitos, la venganza del marido le acarrearía la declaración de enemistad y el pago de la correspondiente calońa, como un acto ilícito, no amparado por la ley penal. Téngase en cuenta que las tres primeras circunstancias también se encuentran en los restantes fueros respecto de la venganza (sea homicida o no) tras el adulterio uxorio no amparada por resolución judicial alguna, y, asimismo, concurren en la mayoría de los casos de violencia en caliente por parte del marido que hemos podido constatar en la literatura no jurídica, dentro del período temporal que nos convoca ${ }^{28}$. Por otra parte, en este punto, si bien en un análisis meramente técnico jurídico de los fueros únicamente apreciamos el reconocimiento al marido de su derecho a vengarse de forma privada, las fuentes no jurídicas permiten que exploremos una perspectiva íntimamente relacionada y que nos conduce por la dimensión social de esta cuestión, en la medida en que constatamos una ausencia absoluta de reproche moral frente a esta explosión de violencia y de carácter. Así pues, estas fuentes nos permiten interpretar el reconocimiento de la venganza del marido en los mencionados fueros dentro de su contexto cultural, tanto como nos abren la puerta para explorar una dimensión simplemente insinuada en las normas, pero que nos confirma la lectura detenida de la literatura no jurídica del período.

Como ejemplo del ejercicio de esta venganza privada en la literatura no jurídica del siglo XIII, que reúne las tres características anteriormente mencionadas, transcribiremos una reacción violenta contra el adúltero que hallamos en el libro de Calila e Dimna, que, si bien no se concreta en la muerte del adúltero, posee interés desde el punto de vista jurídico, en tanto que la pieza nos sitúa en el momento en que el delincuente varón es capturado por el marido, hecho preso por este y llevado ante el Rey para que le aplique justicia por su adulterio. Además, en dicha pieza podemos apreciar cómo el marido hirió gravemente al amante de su mujer, al descubrirlo en flagrante delito, y cómo lo llevó ante el Rey sin miedo alguno de ser juzgado por la violencia que empleó, ni de exponer públicamente su caso, una vez desatada la reacción de furia vindicativa. Dicho episodio, era narrado en esta pieza bajo los siguientes términos, principalmente en forma dialogada:

26 Respecto del ejercicio de la violencia homicida, desconectada de un proceso legal previo que la legitime, veremos la exigencia de la flagrancia del delito para que la ley amparase la actuación violenta del marido en todas las leyes que aquí analizaremos. No obstante, dentro del territorio peninsular, pero fuera del territorio de Castilla y de León y de la época que nos convoca, sí podemos comprobar la existencia de una norma portuguesa otorgada por el rey Dinis que amparaba el ius occidendi contra la mujer adúltera en unos términos desconocidos para la Corona de Castilla. Se trata de una ley contenida en el Livro de as Leis e as Posturas, por virtud de la cual expresamente se reconocía como un derecho la venganza homicida ante el adulterio uxorio sin proceso previo y, además, no se exigía la flagrancia del delito para su reconocimiento, en los términos previstos en L. LeisPosturas p. 82.

27 Un precedente interesante en el derecho espańol respecto de esta posibilidad de eximir de pena al marido que hubiera pretendido matar a ambos, aunque no lo hubiera conseguido, lo encontramos en la ley xxxiv del fuero breve de Miranda de Ebro, previo al siglo xiı y único fuero anterior a este siglo donde encontramos el amparo legal a la venganza del cornudo en Castilla y León, más allá del Liber Iudiciorum, cuya redacción corresponde a un período histórico diferente.

28 Cf. nota 18 . 
LA VIOLENCIA DEL CORNUDO COMO REACCIÓN ANTE EL DELITO DE ADULTERIO. UN ESTUDIO INTERDISCIPLINAR DE LA REGULACIÓN CASTELLANOLEONESA DEL SIGLO XIII PLÁCIDO FERNÁNDEZ-VIAGAS ESCUDERO

(...) Et la muger cavo vn caño desde su casa fasta la calle, çerca del pozo do tenien el agua. Et aparejo vna llaue al caño con miedo que, sy su marido veniese a desora, que posiese ay a su amigo et que lo çerrase desuso.

Asy que vn dia, seyendo su amigo con ella, dixeron le que su marido estana a la puerta. Dixole la muger: "Sal apriesa por el caño que esta açerca del pozo».

Et el detovo se de yr a aquel lugar. Et acaeçio que el pozo era caydo. Et tornose a ella et dixole: "Ya llegue fasta el pozo et fallelo caydo".

Dixo la muger: "Non te dixe yo del pozo sy non por te guiar ende al caño. Escondete et vete».

Dixo el: "Non deuieras tu decir çerca del pozo, pues non avia ay pozo en que herrase yo».

Dixo ella: "; Guay de ty! Escondete e vete e dexa la locura et tornate».

Dixo el: "¿Commo yre, aviendome tu ya rreboluido?".

Et non çeso de dezir, fasta que entro el dueño de casa e prendiole et feriolo muy mal et leuolo preso ante el rrey ${ }^{29}$.

Por otra parte, y aunque se trataba de una reacción amparada legalmente, esta venganza del marido, cuando se aplicaba sobre su propia mujer y acarreaba su muerte, excedía claramente el derecho genérico de corrección marital prevista en diversos fueros de la época ${ }^{30}$, así como en la literatura del siglo XIII. A este respecto, en la General Estoria podemos leer específicamente el siguiente consejo, puesto en boca del rey Alejandro, y referido a la necesidad de castigar a la mujer: Conviene que el hombre (...) haya fuerça pora castigar a su mugier e sos fijos e su compaña, otrossi fuera de su casa en todo logar ó fuere debe aver vergüenca $(. . .)^{31}$. Por el contrario, esta venganza vindicativa, como vemos, se configuraba en los fueros no como un derecho genérico, sino como una medida excepcional en defensa del honor ofendido, que, desde un enfoque sociológico, permitía al marido librarse de la contaminación simbólica derivada, pero que solo encontraba amparo legal de concurrir determinadas circunstancias.

Más allá de este primer supuesto, ha de mencionarse que la familia de CuencaTeruel también amparaba una venganza ejecutada por el marido exclusivamente sobre el adúltero, consistente en la castración del mismo, siempre que fuere sorprendido en flagrante delito por el marido y la venganza fuese ejecutada de forma inmediata, en los términos previstos en la ley Xvi del capítulo XII de la forma sistemática del fuero de Cuenca: Quicumque alium hominem castrauerit, pectet ducentos aureos, et exeat inimicus; si negauerit, saluet se cum duodecim uicinis, uel pugnet. Verumptamen si cum uxore sua,

29 Calila pp. 139-140.

30 Varios fueros municipales expresamente excluían de toda consecuencia jurídica adversa al marido respecto de los daños físicos e incluso de la muerte provocada en su mujer como resultado del ejercicio legítimo de la corrección marital, como puede comprobarse en las siguientes leyes de la familia del fuero de León: F. León 62, F. Parga 38, F. Llanes 65 y F. Benavente 9. Bajo esta misma mentalidad, posteriormente, en el siglo xiv, en el fuero de Vigueras y Val de Funes se castigaba con sesenta sueldos a los parientes de la mujer que persiguieren al marido que la hiriese, cf. F. Vigueras 84.

31 GE. 4.2: 427. Más allá de lo establecido en la historiografía alfonsí, para comprobar el reflejo de la corrección marital en la literatura medieval, cf. LACARra SANZ, Eukene. «El peor enemigo, el enemigo en casa». Clío \& Crimen, 2008, vol. 5, pp. 228-266 y García Herrero, María del Carmen. «La marital corrección: un tipo de violencia aceptado en la Baja Edad Media». Clío \& Crimen, 2008, vol. 5, p. 39-71, entre otros. 
LA VIOLENCIA DEL CORNUDO COMO REACCIÓN ANTE EL DELITO DE ADULTERIO. UN ESTUDIO INTERDISCIPLINAR DE LA REGULACIÓN CASTELLANOLEONESA DEL SIGLO XIII PLÁCIDO FERNÁNDEZ-VIAGAS ESCUDERO

uel fila fuerit deprehensus, et eum caponauerit, nichil pectet ${ }^{32}$. Pero esta no se trataba de una cuestión meramente regulada en la teoría, sin aplicación práctica. No en vano, nos encontramos con la fazaña contenida en la ley cxvi del Libro de los fueros de Castilla, que recogía un supuesto semejante. En concreto, dicha ley constataba la condena judicial contra un marido que no ejecutó la venganza homicida sobre su mujer adúltera, pero sí sobre su amante sorprendido in fraganti, al que mató como resultado de una castración que fue más allá de los límites permitidos ${ }^{33}$. Por esta castración excesiva, y por focalizar la venganza homicida solo sobre el amante, el rey Fernando no eximió de pena al marido, y lo condenó a muerte ${ }^{34}$.

En este punto, téngase en cuenta que la castración del criminal sexual no era un castigo extraño al derecho histórico español. A este respecto, véase el castigo al sodomita previsto en el Liber Iudiciorum ${ }^{35}$, que también se aprecia posteriormente en el Fuero Real $^{36}$. Asimismo, en la literatura no jurídica medieval, previa a la familia de fueros que nos interesan, encontramos este castigo para los delincuentes sexuales, concretamente en el Códice Calixtino, donde lo contemplamos asignado para el corruptor de una muchacha, en un relato en el que se focaliza el castigo corporal en el órgano por el que se expresa la lujuria ${ }^{37}$.

La otra gran familia de fueros extensos del territorio castellanoleonés es la de CoriaCima-Côa. En este derecho, al igual que en el anterior, y siguiendo también la línea del derecho visigodo ${ }^{38}$, se establecía la necesidad de ejecutar la venganza ineludiblemente sobre ambos delincuentes sorprendidos en el acto por el propio sujeto ofendido, y amenazado por unos hechos que podrían acarrearle la burla de la comunidad y un daño irreparable para su fama y su propia estima. Sin embargo, a diferencia de la familia de

32 Dentro de los fueros castellanoleoneses de esta familia, encontramos también esta ley en F. Cuenca 319, C. Valentino 2.2.8, F. Béjar 371, F. Zorita 288, F. Úbeda 30.2, F. Iznatoraf 290, F. Sabiote 291, F. Andújar 270, F. Huete 240, F. Alcaraz 4.69, F. Alarcón 273, F. Alcázar 273 y F. Plasencia 56 (respecto de este último fuero, véase lo ańadido a la anterior norma por la ley 58 , sin precedentes en el derecho de la familia). Fuera de nuestro ámbito territorial, pero dentro de la familia de Cuenca-Teruel, cf. F. Teruel 396 y F. Albarracín f. 77r. Como puede comprobarse, la mencionada norma también establecía que el padre podía castrar al que encontrara fornicando con su hija sin sufrir reproche penal alguno, pero, al igual que Alberto García Ulecia (cf. Los factores de diferenciación entre las personas en los fueros de la Extremadura castellano-aragonesa. Sevilla: Universidad de Sevilla, 1975, pp. 265-263), interpretamos que la ley se refería en este caso únicamente a las hijas no casadas, pues los textos no especificaban que la fornicadora estuviese unida matrimonialmente.

33 Al igual que Rodríguez Marín, José Luis. "Los efectos sociales del adulterio femenino». En TriLlo SAN José, Carmen (coord.). Mujeres, familia y linaje en la Edad Media. Granada: Universidad de Granada, 2004, p. 139 y que BAzÁN, Iñaki, «Las venganzas de honor en los casos de adulterio: el uxoricidio honoris causa». En DíAz Sánchez, Pilar; Franco, Gloria A. y Fuente Pérez, María Jesús (eds.). Impulsando la historia desde la historia de las mujeres. Huelva: Universidad de Huelva, 2012, pp, 249-258, interpretamos que el amante falleció a causa de las heridas provocadas por su castración, si bien la redacción es un tanto oscura en este punto.

34 Probablemente en aplicación de L. Iudiciorum 3.4.4.

35 Cf. L. Iudiciorum 3.5.6.

36 Cf. F. Real 4.9.2.

37 Cf. C. Calixtino 9.17.

38 Cf. L. Iudiciorum 3.4.4. 
LA VIOLENCIA DEL CORNUDO COMO REACCIÓN ANTE EL DELITO DE ADULTERIO. UN ESTUDIO INTERDISCIPLINAR DE LA REGULACIÓN CASTELLANOLEONESA DEL SIGLO XIII PLÁCIDO FERNÁNDEZ-VIAGAS ESCUDERO

Cuenca-Teruel, pero siguiendo la tradición jurídica visigoda ${ }^{39}$, se admitía expresamente el ejercicio de la venganza protectora de la honra no solo por el marido de bendiciones, sino también de juras, y, además, aunque la cuestión no sea objeto principal de nuestro análisis, cualquier pariente de la mujer hasta el segundo grado podía vengarse en el acto sin recibir reproche penal alguno. Por otra parte, y ahondando en estas divergencias, la reacción vindicativa únicamente quedaba amparada en estos fueros en caso de muerte de ambos adúlteros, pues no se mencionaba la circunstancia de que alguno escapase herido de la virulenta respuesta, como en la familia de Cuenca-Teruel. En concreto, y con una retórica imperativa, la ley LIX del fuero de Coria establecía que: Qui fallar ome con su mugier o con su parienta fasta segundo, si ovier marido de bendiciones o a juras, matelos anbos sin calonna ninguna, e non ixca por enemigo. Esi matare el varon e non la muger, peche el coto e ixca por enemigo $0^{40}$.

En cuanto a la traducción del derecho visigodo a mediados del siglo xIII, en el Fuero Juzgo se reconocía esta facultad vindicativa de carácter privado bien como defensa del honor en un supuesto de adulterio flagrante, bien como respuesta tras el proceso que la legitimase, sin modificaciones reseńables respecto de lo dispuesto en el Liber. Así, en el primer caso, y recuperando la ampliación del ius occidendi del marido de la época romana tardoimperial ${ }^{41}$, se concedía al varón que sorprendiera en adulterio a su mujer o a la que con él se hubiera desposado el derecho de matar en caliente a los dos delincuentes conjuntamente ${ }^{42}$. En el segundo, luego del proceso, se reconocía a este sujeto agraviado la

39 Cf. Ibídem.

40 Respecto de los demás fueros de la familia, esta norma también puede contemplarse en F. Cáceres 64, F. Usagre 66, F. Castel-Rodrigo 3.28, F. Alfaiates 42, F. Castel-Melhor 97 y F. CasteloBom 61.

41 Sobre este particular, véase el contenido de la ley 25 de la Lex Romana Burgundionum, de la que hemos de inferir que el derecho a matar a la mujer adúltera sorprendida en adulterio fue establecido ya por el emperador Mayoriano. Sobre este particular, y para apreciar el ensanchamiento del ius occidendi del marido desde la Lex Iulia hasta la regulación visigoda, véase el trabajo de Álvaro D’Ors (cf. Estudios visigóticos II. Roma-Madrid: Consejo Superior de Investigaciones Científicas, 1960, pp. 144-147).

42 «Si el marido ó el esposo mata la muier hy el adulterador, non peche nada por el omecillo» (F. Juzgo 3.4.4). La equiparación de la desposada y de la mujer casada en materia de punición del adulterio encuentra sus precedentes en el derecho romano (cf. Dig. 48.5.14 (13)), y, como tuvimos ocasión de analizar, también se halla, con posterioridad, en diversos fueros municipales castellanos de la Edad Media.

Respecto de la ley siguiente del Fuero Juzgo, para José María García Marín la misma no contemplaba específicamente un supuesto de adulterio en sentido estricto, sino que se empleaba el término en un sentido amplio, referido a las uniones sexuales extraconyugales, ya que no se mencionaba la circunstancia de que la adúltera hubiera de estar ligada matrimonialmente (cf. «La legítima defensa», pp. 422-423), como, efectivamente, puede comprobarse en su redacción:

Si el padre mata la fia que faze adulterio en su casa del padre, non aya nenguna calonna ni ninguna pena. Mas si la non quisiere matar, faga della lo que quisiere é del adulterador, é sean en su poder. Esi los hermanos ó los tios la fallaren en adulterio despues de la muerte de su padre, áyanla en poder á ella y al adulterador, é fagan dellos lo que quisieren (F. Juzgo 3.4.5).

A lo dicho por este autor hemos de añadir que este empleo en un sentido amplio o laxo del término adulterio puede apreciarse sin ningún género de dudas en otras leyes de este mismo título, cf. F. Juzgo 3.4.7, 3.4 .8 y 3.4.14, como en el supuesto similar de F. Juzgo 3.2.3, por lo que, en nuestra opinión, sería erróneo inferir de su redacción que la ley $\mathrm{v}$ regulase necesariamente la fornicación de la mujer casada. Sobre este particular, respecto al concepto amplio de la voz adulterio en este cuerpo jurídico, véase el muy recomendable 
LA VIOLENCIA DEL CORNUDO COMO REACCIÓN ANTE EL DELITO DE ADULTERIO. UN ESTUDIO INTERDISCIPLINAR DE LA REGULACIÓN CASTELLANOLEONESA DEL SIGLO XIII PLÁCIDO FERNÁNDEZ-VIAGAS ESCUDERO

facultad de castigar libremente a los adúlteros, para lo que habían de ser metidos en poder de este ${ }^{43}$. No obstante, si el delito hubiera sido cometido por la desposada, entonces se indicaba que los adúlteros habían de ser entregados al desposado en calidad de $\operatorname{siervos}^{44}$.

Más allá de estas normas, el Fuero Juzgo contempló una forma delictiva de adulterio, que no observamos en ningún otro fuero castellanoleonés, consistente en la relación sexual de una mujer libre con un hombre casado, que fue introducido en el Liber probablemente por influencia gótica ${ }^{45}$. En este caso, la ley únicamente consideraba a la adúltera como delincuente, y establecía que, de demostrarse la acusación, esta fuera metida en poder de la mujer casada ofendida, para que pudiera vengarse a su gusto, sin reproche penal alguno ${ }^{46}$. Sobre este particular, si bien en los fueros municipales apenas podemos extraer información sobre este tipo de disputas entre las mujeres por razón del adulterio, en la literatura no jurídica de la época sí hallamos rastros más significa-

trabajo de Victoria Rodríguez Ortiz en materia de transgresiones sexuales (cf. Historia de la violación. Su regulación jurídica hasta fines de la Edad Media. Madrid: Consejería de Educación y Cultura de la Comunidad de Madrid, 1997, pp. 176-177). En cuanto a las distintas opiniones de los juristas sobre la cuestión de si la hija referida había de ser casada, cf. Osaba García, Esperanza. El adulterio uxorio en la Lex Visigothorum. Madrid: Marcial Pons, 1997, pp. 123-124. En este punto, de optar por la interpretación que nosotros proponemos, podría entonces encontrarse un antecedente interesante, aunque no idéntico, en el derecho visigodo respecto de la venganza familiar prevista contra la pariente fornicaria en el derecho de la familia de Coria-Cima-Côa (cf. F. Coria 58, F. Cáceres 53, F. Usagre 65, F. Castel-Rodrigo 3.28, F. Alfaiates 41, F. Castel-Melhor 97 y F. CasteloBom 60).

Por último, en cuanto al origen de esta norma transcrita del Fuero Juzgo en la tradición jurídica germánica, véase el trabajo de Zeumer, Karl. Historia de la Legislación Visigoda. Barcelona: Universidad de Barcelona, 1944, p. 251.

43 Esta cuestión fue regulada tanto en la ley I, del capítulo IV, del libro III, como, con mayor detalle en materia procesal, en la ley iII del mismo capítulo. Para un repaso a las distintas opiniones entre los juristas sobre ambas leyes y, especialmente, sobre el alcance de la venganza, que debe entenderse que amparaba incluso el homicidio, véanse los trabajos de Osaba García, El adulterio, pp. 88-106 y Álvarez Cora, Enrique. «Derecho sexual visigótico». Historia. Instituciones. Documentos, 1997, vol. 24, pp. 23-24. Por otra parte, véase cómo el Fuero Juzgo también preveía que los bígamos que consumasen su matrimonio fueran metidos en poder del marido, para que este libremente se tomase venganza, cf. F. Juzgo 3.2.6.

Analizaremos la influencia de esta norma en el Fuero Real en adelante. Pero téngase en cuenta que, en territorio peninsular y antes del siglo xiII, en la época de los fueros breves, ya apreciamos esta norma en Portugal, concretamente, dentro de la familia del fuero de Salamanca, en los fueros de Freixo, Orrio y Santa Cruz.

44 Cf. F. Juzgo 3.4.2. Respecto de las diferencias entre la entrega en poder y el sometimiento a servidumbre en el derecho visigodo, véase el estudio ya varias veces mencionado de OrLandis Rovira, "Las consecuencias», pp. 64-65. Sobre este tema también reflexionan Esperanza Osaba García en su trabajo sobre el adulterio en el derecho visigodo (cf. El adulterio, pp. 319-324) y Javier Alvarado Planas (cf. «La influencia germánica»).

45 Cf. Zeumer, Historia, p. 255.

46 «Ley antigua. Si la muier libre faze adulterio con el marido aieno. Si la muier puede seer provada que faze adulterio con marido aieno, sea metida en poder de la muier daquel marido con quien fizo el adulterio, que se vengue della cuemo se quisiere» (F. Juzgo 3.4.9).

Por otra parte, dada la redacción de esta ley, no podemos sostener la afirmación de J. M. Mendoza Garrido, para quien en el Fuero Juzgo no se consideraba parte ofendida a la mujer en caso del adulterio de su marido (cf. "Mujeres adúlteras en la Castilla medieval: delincuentes y víctimas», Clío \& Crimen, 2008 , vol. 5, p. 166). 
tivos, como demuestra la cantiga de Santa María de Alfonso X número 68, en la que apreciamos cómo la mujer de un comerciante reza a la Virgen para causar la desgracia sobre la que fornicó con su marido, mientras que no manifiesta el mismo rechazo hacia su marido. A este respecto, véase también la narración de origen pagano de la venganza de Juno contra Sémele, por haber mantenido relaciones sexuales con su marido, en la General Estoria ${ }^{47}$.

Ciertamente, a través del derecho foral y de la literatura castellana, podemos comprobar un hecho innegable, que las relaciones sexuales ocasionales del marido al margen del matrimonio no eran consideradas como delictivas, ni recibían el mismo rechazo moral que el adulterio de su par en Castilla ${ }^{48}$, aunque también podían generar efectos sociales de menor intensidad en contra del marido adúltero, además de las consecuencias previstas en el derecho de familia ${ }^{49}$. Mientras que, por el contrario, el adulterio de la mujer dańaba con especial virulencia a la propia estima de su marido y atacaba frontalmente su honor de cara a la comunidad. Ello nos ayuda a comprender que el derecho de la época no solo castigase duramente a los culpables del adulterio uxorio, sino que, en defensa del honor del varón, también configurase en clave penal los denuestos de palabra o de hecho al cornudo, así como el hecho de alabarse de la mujer ajena, en los términos previamente analizados, en el apartado primero de este estudio ${ }^{50}$.

Por último, la posibilidad de evitar la contaminación simbólica por parte del marido mediante una explosión de violencia que reivindicase su virilidad y carácter ante sí y ante la comunidad, bajo el amparo legal, también la hallamos en el derecho municipal alfonsí. De esta manera, en el Fuero Real se eximía de responsabilidad al marido que, en caso de

47 Cf. GE. 2.1: 212-213. Para encontrar un caso de venganza homicida de la mujer abandonada y ultrajada en la literatura, cf. GE. 3.1: 312.

48 En cuanto al derecho, y respecto del rechazo que generaba en el campo social la actitud sexual desviada de la mujer, véase especialmente, y más allá del delito de adulterio femenino, la regulación del delito de denuestos en los fueros castellanos, donde con asiduidad eran recogidos los vocablos puta o ceguladera (o sus sinónimos) como injurias verbales a la mujer, lo que demuestra la baja consideración social que recibían las mujeres que ejercían su sexualidad fuera del matrimonio, y que no tenía parangón respecto de los hombres. Respecto de este tema, y en cuanto al desprecio de las mujeres promiscuas en la literatura no jurídica del siglo XIII, cf. FernándeZ-VIagas Escudero, «De los alcahuetes», pp. 223-224.

49 Sobre este particular, véase el trabajo sobre los efectos del adulterio en sociedad de Marín RodríGUEZ, «La legítima defensa», pp. 176-182.

50 Todo lo cual nos lleva a compartir la opinión de la mayoría de los investigadores sobre la materia, que consideraban que, en este contexto, las venganzas privadas sobre la mujer adúltera respondían principalmente a una cuestión de honor, aunque no negamos el papel de otras dinámicas y bienes en juego. En todo caso, sí nos alejamos parcialmente de la opinión expresada por Alfonso Antón, Isabel. «¿Muertes sin venganza? La regulación de la violencia en ámbitos locales (Castilla y León, siglo XIII)». En Rodríguez, Ana (coord.). El lugar del campesino. En torno a la obra de Reyna Pastor. València: Universitat de València, 2007, pp. 261-287, en su estudio más genérico sobre las venganzas medievales de sangre, donde la autora parece extraer conclusiones generales solo de dos casos estudiados, y no presenta la diversidad de venganzas amparadas legalmente en la época, algunas de las cuales se habían de ejecutar en caliente, sin declaración de enemistad previa, como una explosión violenta de ira. A este respecto, y en cuanto a la cuestión terminológica, nos separamos de la mencionada autora y compartimos la opinión mayoritaria, al definir estas venganzas como privadas, ya que no eran ejecutadas por verdugo alguno, sino por particulares, $y$, en muchos casos, como estamos comprobando, en la intimidad del hogar. 
LA VIOLENCIA DEL CORNUDO COMO REACCIÓN ANTE EL DELITO DE ADULTERIO. UN ESTUDIO INTERDISCIPLINAR DE LA REGULACIÓN CASTELLANOLEONESA DEL SIGLO XIII PLÁCIDO FERNÁNDEZ-VIAGAS ESCUDERO

flagrante adulterio, y en cualquier lugar que esto ocurriese, matare al amante de su mujer, en los siguientes términos: Todo home que matáre à otro à sabiendas, muera por ello, salvo si (...) le falláre dormiendo con su muger, do quier que lo fallase ${ }^{51}$.

En cuanto a la venganza después del proceso, por influjo visigodo ${ }^{52}$ y en virtud de la ley I, del título vis, del libro IV, los adúlteros, además de sufrir las consecuencias patrimoniales previstas en la norma, eran condenados a quedar en poder del marido para que este pudiera matar a ambos conjuntamente (en este caso no podía dejar a uno con vida si mataba al otro) o infringirles otro tipo de daño o perjuicio ${ }^{53}$. Por otra parte, pero también bajo la influencia legislativa visigoda, se disponía que, de ser la adúltera mujer desposada, los culpables habrían de pasar en calidad de siervos a disposición del desposado, que tenía prohibido matarlos, y además habrían de padecer las consecuencias patrimoniales derivadas del delito ${ }^{54}$.

51 F. Real 4.17.1, que no se separaba apenas de lo que podemos leer en Collatio 4.3.1. Extrańamente, y quizás por hallarse ubicada en el título de los homicidios, esta circunstancia eximente ha sido pasada por alto por una gran variedad de investigadores que han estudiado el adulterio en el Fuero Real, lo que, en alguna medida, distorsiona el análisis del delito. Ello puede comprobarse en los trabajos de PerEDA, Julián. «El uxoricidio». Anuario de Derecho Penal y Ciencias Penales, 1951, vol. 4, n.o 3, p. 520; GaCto Fernández, Enrique. «La filiación no legítima en la historia del Derecho español». Anuario de Historia del Derecho Español, 1971, vol. 41, pp. 912-913; Machado Carillo, Mario J. El adulterio en el derecho penal. Pasado, presente y futuro. Madrid: Universidad Complutense de Madrid, 1977, p. 45; García Marín, "La legítima defensa", pp. 435-436; Collantes de Terán de la Hera, María José. «El delito de adulterio en el derecho general de Castilla». Anuario de Historia del Derecho Español, 1996, vol. 66, pp. 201-228; BAzÁN, "Las venganzas de honor»; y Abascal Monedero, Pablo José. La infidelidad y el adulterio en España (Estudio histórico-legal). Córdoba: Universidad de Córdoba, 2009, p. 77. No así en Aguilar Ros, Paloma. El adulterio. Discurso jurídico y discurso literario en la Baja Edad Media. Granada: Universidad de Granada, 1990, p. 113 y MendozA GARRIDO, «Mujeres adúlteras», pp. 167-168, donde oportunamente se reseña esta circunstancia.

52 Cf. L. Iudiciorum 3.4.1 y 3.4.3 (y F. Juzgo 3.4.1 y 3.4.3). No obstante, en estas normas de derecho visigodo se permitía al marido ofendido matar sólo a uno de los culpables y dejar al otro con vida, además los conceptos de violación y adulterio estaban entrelazados en estas leyes visigodas, mientras que en el Fuero Real la diferenciación era clara entre ambos (sobre la distinción de ambos conceptos en este cuerpo legislativo alfonsí, cf. Rodríguez Ortiz, Historia de la violación, pp. 317-318). Por su parte, tanto Pereda, «El uxoricidio", p. 520, como Collantes de Terán de la Hera, "El delito de adulterio», p. 219, parecen entender que la inspiración de F. Real 4.7.1 fue F. Juzgo 3.4.4, lo que constituye un error manifiesto en nuestra opinión, pues esta última norma no regulaba la venganza privada tras un proceso judicial, como sí hacía la mencionada ley del Fuero Real, sino el homicidio como legítima defensa del honor en caso de flagrante delito.

53 Sy muger casada fiziere adulterio, ella y el adulterador ambos sean en poder del marido: e faga dellos lo que quisiere, e de quanto han: assi que no pueda matar al vno e dexar al otro: pero si fijos derechos ouieren amos, o el vno de ellos, hereden sus bienes: e si por auentura la muger no fue en culpa, e fuere forçada, no aya pena (F. Real 4.7.1). Para una mayor concreción sobre el ejercicio del ius occidendi, véase el complemento que aporta a esta norma la ley xciı de las Leyes del Estilo. A nuestro entender, José María García Marín (cf. «La legítima defensa», pp. 435-436) interpreta erróneamente como una defensa legítima en caso de flagrante delito lo que, por influjo de L. Iudiciorum 3.4.1 y 3.4.3, como ha sido previamente explicado, constituye un supuesto de violencia posterior al proceso, con la correspondiente traditio de los adúlteros al marido. Por otra parte, de hacer caso a José María García Marín, esta norma entraría en una colisión irresoluble con el ejercicio de la venganza privada en caso de flagrante delito regulado en F. Real 4.17.1, que no amparaba el ius occidendi ejercido sobre ambos, sino únicamente sobre el amante.

54 Si muger desposada derechamente casare con otro, o fiziere adulterio, el y ella con sus bienes sean metidos en poder del esposo, assi que sean sus sieruos: mas que no los puede matar: e otro si de sus bienes que faga lo que quisiere, si ninguno dellos no ouiere fijos derechos (F. Real 4.7.2). Véase la evidente inspiración de esta ley en L. Iudiciorum 3.4.2. 
LA VIOLENCIA DEL CORNUDO COMO REACCIÓN ANTE EL DELITO DE ADULTERIO. UN ESTUDIO INTERDISCIPLINAR DE LA REGULACIÓN CASTELLANOLEONESA DEL SIGLO XIII PLÁCIDO FERNÁNDEZ-VIAGAS ESCUDERO

\section{La venganza privada del marido ante el adulterio en las Partidas}

En las Partidas nos encontramos con una reducción considerable del ius occidendi del marido sobre su mujer adúltera respecto de la legislación previa, en consonancia con la reducción de los espacios dejados a la venganza privada en este código normativo y con la consecuente ampliación del ius puniendi del rey ${ }^{55}$, en un intento de fortalecimiento del poder regio emprendido por Alfonso X en su obra jurídica, sustentado en buena medida bajo esquemas explicativos de índole teológica ${ }^{56}$, que tiene aquí una derivada interesante en materia de derecho penal. De esta forma, y principalmente siguiendo esquemas procedentes del derecho romano ${ }^{57}$, se permitió el homicidio ejecutado por el padre contra

55 Sobre este proceso de reducción de los espacios de la venganza privada a favor de la justicia del rey el derecho histórico español, desde la Baja Edad Media en adelante, con especial atención en la obra jurídica de Alfonso X, cf. Tomás y VALIEnTe, Francisco. El derecho penal de la monarquía absoluta: (siglos XVI, XVII y XVIII). Madrid: Tecnos, 1969 y Barros, Jose d'Assunção. "A conquista régia do monopólio da violência física e simbólica, e sua expressão literária nas crônicas e cantigas da Idade Média Ibérica». Floema, 2014, vol. 10, pp. 113-138. Para conocer las principales aportaciones historiográficas sobre el proceso de formación del monopolio estatal de la violencia en el feudalismo en la Europa occidental, resulta de utilidad consultar la obra de López Rasch, Juan Cruz. "El monopolio de la violencia en el feudalismo como problema historiográfico». Anuario de la Facultad de Ciencias Humanas, 2012, vol. 10, p. 1-16.

56 Téngase en cuenta que la supresión de espacios dejados a la venganza privada y el mayor de poder punitivo del rey en este código, encaja con el consabido rol del monarca como vicario de Cristo en las Partidas, así como con su misión salvífica en su reino, y con el papel de la ley regia en este esquema general, como receptáculo del derecho divino. Para un estudio detenido sobre estos principios informativos, no carentes de excepciones y matizaciones a lo largo del código alfonsí, cf. FERnÁndez-Viagas Escudero, «El rey en las Partidas».

57 Téngase en cuenta, como hemos indicado en otros trabajos, que cuando en la Séptima Partida se citaba como fuente de autoridad en materia de adulterio a los sabios antiguos, el legislador se refería a los antiguos juristas romanos, cuya labor se encuentra reflejada en el Código Justiniano o en el Digesto. Ello puede ser constatado fácilmente, puesto que en tales casos el código alfonsí empleaba una norma extraída de la vieja Lex Iulia de adulteriis coercendis, como puede comprobarse si conectamos estas menciones en Partidas 7.17.1 con C. Justiniano 9.9.1 y en Partidas 7.17.14 con Dig. 48.5.24 (23). Sobre la influencia romana en las Partidas en la regulación penal en materia de adulterio, tiene todavía hoy sentido repasar las anotaciones del licenciado Gregorio López al título Xvi del último libro, que pueden consultarse en la edición de las Partidas que aparece en el apartado final de este artículo, así como obras escritas con posterioridad, como Groizard y Gómez de la Serna, Alejandro. El código penal de 1870, comentado y concordado. Tomo V. Salamanca: Esteban-Hermanos, Impresores, 1894, pp. 22 y 43, BAzÁn Díaz, Ińaki. "El pecado y el delito de adulterio en la Castilla medieval. Transgresiones del modelo de sexualidad conyugal y su castigo». En Arte y sexualidad en los siglos del románico: imágenes y contextos. Aguilar de Campoo: Fundación Santa María la Real del Patrimonio Histórico, 2018, pp. 11-52; y, sobre todo, Morín, Alejandro. «Matar a la adúltera: el homicidio legítimo en la legislación castellana medieval». Cahiers de Linguistique et de Civilisation Hispaniques Médiévales, 2001, vol. 24, pp. 353-380, donde además se realiza un brillante análisis que conecta esta regulación con el derecho canónico de la época y con los problemas que surgen al tratar de encontrar una concordia entre ambas normativas. Con carácter más genérico, respecto de la influencia del derecho romano en las Partidas, cf. PÉrez Martín, Antonio. «Fuentes romanas en las Partidas». Glossae, 1992, vol. 4, pp. 215-246.

Por último, el influjo del derecho justinianeo en la regulación del delito de adulterio puede encontrarse con anterioridad a las leyes alfonsíes en los territorios de Castilla y León, como se pone de manifiesto con la regulación de este delito en los fueros de Parga y de Llanes, levantada parcialmente sobre una ley atribuida a la Lex Iulia por la legislación justinianea, cf. FERnÁndez-Viagas Escudero, Plácido. «El delito de adulterio 
LA VIOLENCIA DEL CORNUDO COMO REACCIÓN ANTE EL DELITO DE ADULTERIO. UN ESTUDIO INTERDISCIPLINAR DE LA REGULACIÓN CASTELLANOLEONESA DEL SIGLO XIII PLÁCIDO FERNÁNDEZ-VIAGAS ESCUDERO

ambos adúlteros conjuntamente ${ }^{58}$, cuyo estudio no corresponde desarrollar en el presente artículo, como también el homicidio por parte del marido, pero únicamente respecto del adúltero en este caso, y solo en tres escenarios posibles, el último de los cuales se explica por una influencia procedente del Liber Iudiciorum.

En el primer escenario, y tomando como referencia el derecho justinianeo ${ }^{59}$, según las Partidas, el marido que encontrase en su casa o en otro lugar apartado a su mujer con aquel a quien previamente hubiera apercibido en tres ocasiones diferentes, por escrito realizado ante omes buenos, por sospechar de que hubiese mantenido relaciones sexuales con su mujer o tratase de hacerlo, podía tomarse la justicia por su mano, en el mismo acto, y dar muerte a dicho amante. Lo que quedaba establecido en los siguientes términos en el código alfonsí:

Sospechando algun ome que su muger faze adulterio con otro, o que se trabaja de lo fazer, deue el marido afrontar en escrito ante omes buenos a aquel contra quien sospecha, defendiendole que non entre en su casa, nin se aparte en ninguna casa, nin en otro lugar, con ella, nin le diga ninguna cosa; porque ha sospecha contra el, que se trabaja de fazer desonrra; e esto le deue dezir tres vezes. E si por auentura, por tal afrenta como esta non se quisiere castigar si el marido fallare despues desso a aquel ome con ella en alguna casa, o lugar apartado, lo matere e non deue recebir pena ninguna porende $(. . .)^{60}$.

Por otro lado, nos encontramos con la venganza del marido, vindicativa de su honor y protectora de la contaminación simbólica antes descrita, contra el que efectivamente hubiera sido por él hallado en flagrante delito. En este escenario, el marido podía ejercer su furia homicida contra el amante únicamente si lo encontrase en plena actividad criminal con su mujer, bien en la casa del propio ofendido o bien en cualquier otro lugar ${ }^{61}$, y siempre que tal individuo fuera de condición $v i^{62}$ y no se hallara en ninguno de los supuestos previstos en la norma. Esta considerable reducción del ius occidendi del marido respecto de lo dispuesto en el derecho municipal previo, en tanto que solo podía ejercitarse sobre una clase de hombres, por cuestiones de jerarquía social, y nunca sobre

en tres fueros de la familia de León-Benavente. Una aproximación interdisciplinar al derecho medieval espańol». Revista de Estudios Histórico-Jurídicos, 2018, vol. 15, pp. 183-212.

58 Cf. Partidas 7.17.14. Véase la fuente de esta norma, dentro del derecho romano, en Dig. 48.5 .23 (22).

59 Cf. Novelas 113.15.

60 Partidas 7.17.12. Véase una redacción semejante de esta norma en Partidas 3.14.12, que específicamente considera como lugares apartados una huerta, una casa apartada fuera de la villa o los arrabales de la misma villa.

${ }^{61}$ Como bien indica el glosador Gregorio López, ello parece ampliar lo dispuesto en Dig. 48.5.25 (24), que únicamente amparaba el homicidio del amante hallado en la propia casa del marido, cf. glosa 2 a Partidas 7.17.13. Téngase en cuenta que esta ampliación está en concordancia con lo dispuesto por el legislador alfonsí en F. Real 4.17.1.

62 Particularmente, por hombre vil hemos de entender plebeyo, en una interpretación sistemática de las Partidas, cf. Collantes de Terán de la Hera, «El delito de adulterio», p. 219. Este derecho de matar al amante plebeyo de la mujer, pero no a esta misma, parece inspirado en Dig. 48.5.25 (24). Respecto de la particular condición social del amante, como requisito para ejercer la venganza homicida del ofendido, también parece claramente inspirado en el derecho romano, como se comprueba de la lectura de la anterior norma, que restringía el derecho de matar al criminal adúltero en función de la condición social de este. 
LA VIOLENCIA DEL CORNUDO COMO REACCIÓN ANTE EL DELITO DE ADULTERIO.

UN ESTUDIO INTERDISCIPLINAR DE LA REGULACIÓN CASTELLANOLEONESA DEL SIGLO XIII PLÁCIDO FERNÁNDEZ-VIAGAS ESCUDERO

la mujer del ofendido, quedaba establecida principalmente por influjo romano en los siguientes términos en el código alfonsí:

El marido que fallare algund ome vil en su casa, o en otro lugar, yaciendo con su mujer, puedelo matar sin pena ninguna, maguer non le ouiese fecho la afruenta que diximos en la ley ante desta. Pero non deue matar la muger, mas deue fazer afruenta de omes buenos, de cómo lo fallo; e de si, meterla en mano del Judgador, que faga della la justicia que la ley manda. Pero si este ome fuere tal, a quien el marido de la mujer deue guardar, e fazer reuerencia, como si fuese su señor, o ome que lo ouiesse fecho libre, o si fuese ome honrrado, o de gran lugar, non lo deue matar porende $(. . .)^{63}$.

Finalmente tenemos un tercer escenario, en el que el legislador abandonó la influencia romana y recuperó la influencia visigótica, crucial para el desarrollo del ius occidendi del marido ante el adulterio uxorio en el derecho castellanoleonés previo, como hemos tenido ocasión de estudiar detenidamente. En este caso, y fruto de lo dispuesto en las leyes IX y x, de los títulos XxIV y XXv, respectivamente, de la Séptima Partida, nos encontramos frente al amparo legal de una venganza ejercitada no en caliente, como en los anteriores casos previstos en el código alfonsí, sino en frío, luego del correspondiente proceso criminal y bajo el respaldo de una sentencia judicial que legitimase un castigo que incluso podía derivar en la muerte de la mujer, si así lo consideraba el marido deshonrado. En concreto, se establecía que si la mujer casada cometía adulterio con un judío o un musulmán, esta había de ser entregada al marido para que pudiera tomarse venganza a su gusto, luego del oportuno proceso penal y bajo la figura rescatada del Liber Iudiciorum

63 Partidas 7.17.13. Respecto de esta norma, Alejandro Morín e Ińaki Bazán analizan la venganza homicida desatada por el adulterio en contraste con las fuentes eclesiásticas, en tanto que las Partidas (y con anterioridad el derecho foral, en los términos expuestos en el apartado previo) reconocían como un derecho lo que para la Iglesia era un pecado mortal, cf. Morín, Alejandro. Pecado y delito en la Edad Media. Estudio de una relación a partir de la obra de Alfonso el Sabio. Córdoba: Ediciones del Copista, 2009, pp. 121-134 y BAzÁN DÍAz, "El pecado y el delito de adulterio», pp. 48 y 49. Respecto de la opinión de la Iglesia sobre el adulterio y su regulación en el derecho eclesiástico, véase también Córdoba DE LA LLAVE, Ricardo. "Adulterio, sexo y violencia en la Castilla medieval». Espacio, Tiempo y Forma. Serie IV, Historia Moderna, 1994, vol. 7, p. 157; GIL, Federico R. La institución matrimonial en la Hispania cristiana bajomedieval (1215-1563). Salamanca: Universidad Pontificia de Salamanca, 1989, pp. 526-530; AguILAR Ros, El adulterio, pp. 159-264; y las obras de Brundage, James A. La ley, el sexo y la sociedad cristiana en la Europa medieval. México: Fondo de Cultura Económica, 2000; «Sex and Canon Law». En Bullough, Vern L. y Brundage, James A. (eds.). Handbook of Medieval Sexuality. New York: Routledge, 1999, pp. 33-50; y "Adultery and Fornication. A Study in Legal Theology". En Bullough, Vern L. y Brundage, James A. (eds.). Sexual Practices and The Medieval Church. New York: Prometheus Books, 1982, pp. 129134. No obstante, a pesar de esta diferencia nuclear, y de otras que no corresponde analizar en el presente estudio, lo cierto es que las leyes de la Séptima Partida que regulaban el adulterio también acusaban una innegable influencia eclesiástica, como se encarga de analizar con detenimiento y solvencia Alejandro Morín en el mencionado trabajo. A los efectos de nuestro artículo, la cuestión que mayor interés nos suscita es la configuración del perdón marital a la mujer adúltera, regulado precisamente bajo un enfoque de origen eclesiástico, como desarrollamos con detenimiento en Fernández-Viagas Escudero, Plácido. «El perdón marital a la adúltera recluida por su delito. Un estudio de historia cultural de la Séptima Partida». Revista Aequitas. Estudios sobre Historia, Derecho e Instituciones, 2007, vol. 9, pp. 7-28, y a cuya lectura nos remitimos. 
LA VIOLENCIA DEL CORNUDO COMO REACCIÓN ANTE EL DELITO DE ADULTERIO. UN ESTUDIO INTERDISCIPLINAR DE LA REGULACIÓN CASTELLANOLEONESA DEL SIGLO XIII PLÁCIDO FERNÁNDEZ-VIAGAS ESCUDERO

de la traditio in potestate ${ }^{64}$. Por lo tanto, únicamente si la mujer ofendía doblemente al marido, no solo por el adulterio en sí, sino además por haberlo realizado con un judío o un musulmán, las Partidas concedían al sujeto ofendido por este adulterio agravado el derecho de matar a su propia mujer. Nótese, además, que en este caso no se le concedía el derecho de matar al amante, quien habría de recibir en este caso la pena pública prevista en las mencionadas leyes.

En este punto, resulta necesario reseñar cómo una gran variedad de especialistas en la regulación del adulterio en las Partidas no han abordado el análisis de este adulterio agravado en sus trabajos o siquiera lo han mencionado en los mismos ${ }^{65}$. Por nuestra parte, entendemos que todo análisis de la regulación del adulterio en las Partidas que no contemple esta forma especial del delito obvia una parte fundamental en la investigación, especialmente si se pretende estudiar la venganza privada del marido como reacción ante el adulterio de su par, dado el contenido de las leyes analizadas de los títulos XXIV y xxv de la Séptima Partida.

\section{Conclusiones}

En una aproximación sociológica al objeto de estudio, hemos tenido ocasión de analizar la venganza del marido ante el adulterio uxorio como la reacción virulenta apropiada para evitar la contaminación por la impureza generada tras la relación sexual ilícita de su mujer, en este contexto simbólico. Así, hemos podido comprobar cómo el marido ofendido protegía su honor amenazado por el atentado sexual con una explosión de furia, que lo presentaba ante la comunidad no ya como un ser pusilánime, sino como un hombre de carácter, que se defendía violentamente si era necesario, ante una de las mayores ofensas que podía recibir. Para ello hemos empleado fuentes de diversa naturaleza, en las que se hace evidente el daño al honor del marido que generaba el adulterio en dicho contexto, así como la aceptación social de la reacción violenta del ofendido, bajo estos parámetros. Como hemos explicado, dichas fuentes han de ser interpretadas desde el auxilio de la

64 Compárese esta traditio con la configurada para el adulterio en el Liber Iudiciorum (cf. L. Iudiciorum 3.4.1), que, asimismo, podemos también contemplar dentro del derecho alfonsí en el Fuero Real (cf. F. Real 4.7.1), por influencia visigótica, como fue previamente explicado. En todo caso, nótese que en las mencionadas leyes del Liber Iudiciorum y del Fuero Real el amante adúltero era también entregado en poder del marido ofendido, a diferencia de lo dispuesto en las mencionadas leyes de la Séptima Partida y en Espéculo 2.15.1, 2 y 6 , en este último caso respecto del adulterio de la parienta de los reyes o de otras mujeres con ellos vinculadas. Para un análisis de la configuración y alcance de esta figura jurídica de la entrega del delincuente a la víctima, para que este se tomase libremente la justicia por su mano tras la celebración del oportuno proceso, cf. nota 42. Por último, para un estudio en mayor profundidad de estas normas de los títulos XXIV y XXV de la Séptima Partida, cf. Fernández-Viagas Escudero, «Las relaciones sexuales».

65 Cf. Pereda, «El uxoricidio», p. 520; Gacto Fernández, «La filiación ilegítima», pp. 912-913; Machado Carrillo, El adulterio, p. 45; García Marín, "La legítima defensa», pp. 435-436; Collantes de Terán de la Hera, «El delito de adulterio»; Abascal Monedero, La infidelidad, p. 77; y Mendoza GARrido, «Mujeres adúlteras», pp. 167-168. Este delito, en cambio, sí ha sido contemplado por diversos especialistas no ya en temas de derecho penal o adulterio, sino en materia de minorías religiosas, como se desarrolla en FERnÁndez-Viagas Escudero, «Las relaciones sexuales». 
sociología, en los términos aquí expuestos, para poder comprender el significado profundo de esta violencia privada consentida por la sociedad contra la mujer adúltera, así como para comprender tanto la impureza, si empleamos un enfoque durkheimiano, como el estigma, si preferimos una aproximación goffmaniana, que, indiscutiblemente, se apegaban al marido que no reaccionaba virulentamente ante el adulterio uxorio.

Por otra parte, desde el punto de vista jurídico, como ha podido comprobarse a lo largo del presente estudio, el derecho previo a las Partidas, por lo general, repetía elementos sustanciales del Liber Iudiciorum en la regulación de la venganza privada en caso de adulterio. En un análisis sucinto habríamos de decir que, mientras que las familias de Cuenca-Teruel y de Coria-Cima-Côa, así como la fazaña de la ley 116 del Libro de los fueros de Castilla, bebían de la regulación visigoda del ius occidendi por delito flagrante, que contemplaba la ejecución de esta venganza sobre ambos adúlteros, el Fuero Real seguía el camino trazado por las leyes del Liber, si bien en materia de venganza privada posterior al juicio, en tanto que lo abandonaba respecto de la venganza en caliente.

Más allá del derecho municipal, nuestro estudio desemboca en la regulación de las Partidas, cuando claramente se rompe con esta línea visigótica en la regulación de la violencia privada, por influencia directa del derecho romano, salvo en el supuesto específico del adulterio de la mujer cristiana con un judío o un musulmán. De tal manera, podemos afirmar que en el derecho alfonsí fueron reducidos los espacios dejados a la venganza privada del marido ofendido por el adulterio como mecanismo de resolución del conflicto en comparación con el derecho previo, así como se afianzó, en lógica consecuencia, el ius puniendi del rey, en un contexto normativo más amplio de fortalecimiento del poder regio.

Estas tres derivadas del análisis aquí propuesto, la sociológica, la jurídica y la política, pueden ser expuestas tras el estudio detenido de unos mismos textos, de tal manera que se enriquezca la labor del investigador y se permita realizar un trabajo interdisciplinar, con el que extraer un conocimiento más profundo de estas leyes. Y a estos fines hemos dedicado el presente artículo.

Barkow, August Friedrich (ed.). Lex romana Burgundionum. Gryphiswalda, 1826.

Bermejo Cabrero, José Luis (ed.). «Un texto afín al Fuero Viejo de Castilla: El Fuero de los fijosdalgos y las Fazañas del Fuero de Castilla». Anuario de Historia del Derecho Español, 1999, vol. 69, pp. 239-274.

Calleja Puerta, Miguel (ed.). El fuero de Llanes. Edición crítica. Oviedo: Sueve, 2003.

Castro, Américo y Onís, Federico de (eds.). Fueros leoneses de Zamora, Salamanca, Ledesma y Alba de Tormes. Madrid: Centro de Estudios Históricos, 1916.

Döhla, Hans-Jörg (ed.). El libro de Calila e Dimna (1251). Zurich: Universidad de Zurich, 2007. Fernández Guerra y Orbe, Aureliano. El fuero de Avilés. Madrid, 1865.

Fita Colomer, Fidel (ed.). «El fuero de Uclés». Boletín de la Real Academia de la Historia, 1889, vol. 14 , pp. 302-355.

Friedberg, Emil (ed.). Corpus Iuris Canonici. Leipzig: Bernhard Tauchnitz, 1879. 
LA VIOLENCIA DEL CORNUDO COMO REACCIÓN ANTE EL DELITO DE ADULTERIO. UN ESTUDIO INTERDISCIPLINAR DE LA REGULACIÓN CASTELLANOLEONESA DEL SIGLO XIII PLÁCIDO FERNÁNDEZ-VIAGAS ESCUDERO

Fuero romanceado de Cáceres. Disponible en línea el pergamino del siglo xiII y la transcripción de M. ${ }^{a}$ Dolores García Oliva en http://www.ayto-caceres.es/ciudad/el-fuero-romanceadotranscripcion

García Blanco, María José (ed.). Liber Sancti Jacobi: Codex Calixtinus. Santiago de Compostela: Xunta de Galicia, 2014.

González Palencia, Ángel y González Palencia, Inocenta (eds.). El fuero latino de Albarracín. Madrid: Tipografía de Archivos, 1932.

Gorosh, Max (ed.). El Fuero de Teruel según los Mss. 1-4 de la Sociedad Económica Turolense de Amigos del País y 802 de la Biblioteca Nacional de Madrid. Stockholm: Almqvist \& Wiksells, 1950.

Gutiérrez Cuadrado, Juan (ed.). Fuero de Úbeda. Valencia: Universidad de Valencia, 1979.

Herculano, Alexandre (ed.). Portugaliae Monumenta Historica. Leges et Consuetudines. Lisboa: Academia das Ciências de Lisboa, 1856.

Keniston, Hayward (ed.). Fuero de Guadalajara (1219). New York: Princeton University Press, 1924.

Kriegel, Albert; Hermann, Emil y Osenbrüggen, Eduardo (eds.). Cuerpo del derecho civil romano, T. V. Barcelona: Jaime Molinas, 1892.

Lacarra, María Jesús (ed.). Sendebar. Madrid: Cátedra, 1989.

Lacarra, María Jesús y Ducay, Esperanza (eds.). Disciplina clericalis. Zaragoza: Guara, 1980.

Los códigos españoles concordados y anotados. Madrid: Imprenta de la Publicidad, 1849.

Luño PeÑa, Enrique (ed.). Legislación foral de don Rodrigo Jiménez de Rada. Zaragoza, 1927.

Majada Neila, Jesús (ed.). Fuero de Plasencia. Plasencia: Ayuntamiento de Plasencia, 1986.

Manuel Rodríguez, Miguel de (ed.). Memorias para la vida del santo rey Don Fernando III. Madrid: En la imprenta de la viuda de Joaquín Ibarra, 1800.

Martín Lázaro, Antonio (ed.). Fuero castellano de Béjar (siglo XIII). Preliminar, transcripción y notas. Madrid, 1926.

Martínez Díez, Gonzalo (ed.). Fueros locales en el territorio de la provincia de Burgos. Burgos: Caja de Ahorros Municipal de Burgos, 1982.

Martínez Martínez, Faustino (ed.). "Antología de textos forales del antiguo reino de Galicia (siglos XII-XIV)». Cuadernos de Historia del Derecho, vol. 10, 2003, pp. 247-352.

Martín de Palma, María Teresa (ed.). Los fueros de Villaescusa de Haro y Huete. Málaga: Universidad de Málaga, 1984.

Menéndez Pidal, Ramón (ed.). Primera Crónica General de España. Madrid: Bailly Baillière, 1906

Mettmann, Walter (ed.). Cantigas de Santa María de Alfonso X el Sabio. Vigo: Edicións Xerais de Galicia, 1981.

Moralejo, Abelardo (dir.). Liber Sancti Jacobi: Codex Calixtinus. Santiago de Compostela: Xunta de Galicia, 2014.

Moreno Casado, José (ed.). Fuero de Baza. Estudio y transcripción. Granada: Universidad de Granada, 1968.

Muñoz y Romero, Tomás (ed.). Colección de fueros municipales y cartas pueblas de los reinos de Castilla, León, Corona de Aragón y Navarra. Madrid: Imprenta de don José María Alonso, 1874.

Porras Arboledas, Pedro Andrés (ed.). «Fuero de Sabiote». Cuadernos de Historia del Derecho, 1994, vol. 1, pp. 243-441.

Pujol, Julio (ed.), Crónica de España por Lucas, obispo de Túy. Madrid: Real Academia de la Historia, 1926.

Quesada Huertas, Pablo (ed.). El fuero de Andújar: Estudio y edición. Jaén: Universidad de Jaén, 2006. 
LA VIOLENCIA DEL CORNUDO COMO REACCIÓN ANTE EL DELITO DE ADULTERIO. UN ESTUDIO INTERDISCIPLINAR DE LA REGULACIÓN CASTELLANOLEONESA DEL SIGLO XIII PLÁCIDO FERNÁNDEZ-VIAGAS ESCUDERO

Rodrigues Lapa, Manuel (ed.). Cantigas d'escarnho e de mal dizer. Ediçáo crítica. Vigo: Editorial Galaxia, 1965.

Roudil, Jean (ed.). Les fueros d'Alcaraz et d'Alarcón. Paris: Faculté des Lettres et Sciences Humanes de Strasburg, 1966.

SÁez SÁnchez, Emilio (ed.). El fuero de Coria. Madrid: Instituto de Estudios de Administración Local, 1949.

Sánchez, Galo (ed.). Fueros castellanos de Soria y Alcalá de Henares. Madrid: Centro de Estudios Históricos, 1919.

Sánchez, Galo (ed.). Libro de los fueros de Castiella. Barcelona: Facultad de Derecho, 1924.

Sánchez-Prieto Borja, Pedro (ed.). General Estoria. Madrid: Fundación José Antonio de Castro, 2009.

Sancho Izquierdo, Miguel (ed.). El fuero de Molina de Aragón. Madrid: Librería General de Vitoriano Suárez, 1916.

Silva, Nuno J. Espinosa Gomes da y Rodrigues, Maria Teresa Campos (eds.). Libro das Leis e Posturas. Lisboa: Facultade de Direito, 1971.

Ureña y Smenjaud, Rafael de (ed.). Fuero de Cuenca. Madrid: Tipografía de Archivos, 1935.

Ureña y Smenjaud, Rafael de (ed.). El Fuero de Zorita de los Canes según el códice 217 de la Biblioteca Nacional (siglo xiii al xiv) y sus relaciones con el Fuero Latino de Cuenca y el Romanceado de Alcázar. Madrid: Establecimiento Tipográfico de Fortanet, 1911.

Ureña y Smenjaud, Rafael de y Bonilla y San Martín, Adolfo (eds.). Fuero de Usagre (siglo XiII). Anotado con las variantes del de Cáceres. Madrid: Hijos de Reus Editores, 1907.

\section{REFERENCIAS BIBLIOGRÁFICAS}

Abascal Monedero, Pablo José. La infidelidad y el adulterio en España (Estudio histórico-legal). Córdoba: Universidad de Córdoba, 2009.

Aguilar Ros, Paloma. El adulterio: Discurso jurídico y literario en la Baja Edad Media. Granada: Universidad de Granada, 1990.

Alcalá-Zamora y Castillo, Nicolás. «Instituciones judiciales y procesales del fuero de Cuenca». Anuario de Estudios Medievales, 1982, vol. 12, pp. 59-132.

Alfonso Antón, Isabel. «¿Muertes sin venganza? La regulación de la violencia en ámbitos locales (Castilla y León, siglo XIII)». En RodríGuez, Ana (coord.). El lugar del campesino. En torno a la obra de Reyna Pastor. Valencia: Universidad de Valencia, 2007, pp. 261-287.

Alvarado Planas, Javier. «La influencia germánica en el fuero de Cuenca. La venganza de la sangre». Iacobus, 2003, vols. 15-16, pp. 55-74.

Alvarado Planas, Javier. «Lobos, enemigos y excomulgados: la venganza de la sangre en el derecho medieval». En Serna Vallejo, Margarita y Baró Pazos, Juan (coords.). El fuero de Laredo en el octavo centenario de su concesión. Laredo: Universidad de Cantabria, 2001, pp. 335-366.

Álvarez Cora, Enrique. «Derecho sexual visigótico». Historia. Instituciones. Documentos, 1997, vol. 24, pp. 1-52.

Barrero García, Ana María y Alonso Martín, María Luz. Textos de derecho local español. Madrid: Consejo Superior de Investigaciones Científicas, 1989.

BArros, Jose d'Assunção. «A conquista régia do monopólio da violência física e simbólica, e sua expressão literária nas crônicas e cantigas da Idade Média Ibérica». Floema, 2014, vol. 10, pp. 113-138. 
LA VIOLENCIA DEL CORNUDO COMO REACCIÓN ANTE EL DELITO DE ADULTERIO. UN ESTUDIO INTERDISCIPLINAR DE LA REGULACIÓN CASTELLANOLEONESA DEL SIGLO XIII PLÁCIDO FERNÁNDEZ-VIAGAS ESCUDERO

BAZÁN, Ińaki, «Las venganzas de honor en los casos de adulterio: el uxoricidio honoris causa». En Díaz Sánchez, Pilar; Franco, Gloria A. y Fuente Pérez, María Jesús (eds.). Impulsando la historia desde la historia de las mujeres. Huelva: Universidad de Huelva, 2012, pp, 249-258.

BAZÁN DíAz, Ińaki. «El pecado y el delito de adulterio en la Castilla medieval. Transgresiones del modelo de sexualidad conyugal y su castigo». En Arte y sexualidad en los siglos del románico: imágenes y contextos. Aguilar de Campoo: Fundación Santa María la Real del Patrimonio Histórico, 2018, pp. 11-52.

Brundage, James A. «Adultery and Fornication. A Study in Legal Theology». En Bullough, Vern L. y Brundage, James A. (eds.). Sexual Practices and The Medieval Church. New York: Prometheus Books, 1982, pp. 129-134.

Brundage, James A. «Sex and Canon Law». En Bullough, Vern L. y Brundage, James A. (eds.). Handbook of Medieval Sexuality. New York: Routledge, 1999, pp. 33-50.

Brundage, James A. La ley, el sexo y la sociedad cristiana en la Europa medieval. México: Fondo de Cultura Económica, 2000.

Caillois, Roger. El hombre y lo sagrado. México: Fondo de Cultura Económica, 1984.

Castillo Lluch, Mónica. «De verbo vedado: consideraciones lingüísticas sobre la agresión verbal y su expresión en castellano medieval». Cahiers de Linguistique et de Civilisation Hispaniques Médiévales, 2004, vol. 27, pp. 23-36.

Collantes de Terán de la Hera, María José. «El delito de adulterio en el derecho general de Castilla». Anuario de Historia del Derecho Español, 1996, vol. 66, pp. 201-228.

Córdoba de la Llave, Ricardo. "Adulterio, sexo y violencia en la Castilla medieval». Espacio, Tiempo y Forma. Serie IV, Historia Moderna, 1994, vol. 7, pp. 153-184.

Douglas, Mary. Pureza y peligro. Madrid: Siglo XXI Editores, 1973.

Durkheim, Émilie. Las formas elementales de la vida religiosa. Buenos Aires: Shapire, 1968.

Fernández-Viagas Escudero, Plácido. «De los alcahuetes. Un estudio del título xxir de la Séptima Partida». Cuadernos de Historia del Derecho, 2017, vol. 24, pp. 219-242.

FernándeZ-Viagas Escudero, Plácido. «El delito de adulterio en tres fueros de la familia de León-Benavente. Una aproximación interdisciplinar al derecho medieval español». Revista de Estudios Histórico-Jurídicos, 2018, vol. 15, pp. 183-212.

FernándeZ-Viagas Escudero, Plácido. «El perdón marital a la adúltera recluida por su delito. Un estudio de historia cultural de la Séptima Partida». Revista Aequitas. Estudios sobre Historia, Derecho e Instituciones, 2007, vol. 9, pp. 7-28.

Fernández-Viagas Escudero, Plácido. «El rey en las Partidas de Alfonso X: su Vicariato Divino y su caracterización bajo esquemas de sacralidad». Hispania Sacra, 2017, vol. 139, pp. 61-80.

Fernández-Viagas Escudero, Plácido. «La honra del marido como bien jurídico protegido en el delito de adulterio. Un estudio de las Partidas a la luz de sus antecedentes normativos y de su contexto legal». Clio \& Crimen, 2016, vol. 13, pp. 53-74.

Fernández-Viagas Escudero, Plácido. «Las relaciones sexuales entre miembros de minorías religiosas y mujeres cristianas en la Séptima Partida. Un estudio interdisciplinar de las leyes 7.24.9 y 7.25.10». En la España Medieval, 2017, vol. 40, pp. 269-308.

Gacto Fernández, Enrique. «La filiación no legítima en la historia del Derecho español». Anuario de Historia del Derecho Español, 1971, vol. 41, pp. 899-944.

García de Valdeavellano, Luis. «El "apellido". Notas sobre el procedimiento in-fraganti en el derecho español medieval». Cuadernos de Historia de España, 1947, vol. 7, pp. 67-105.

García Herrero, María del Carmen. «La marital corrección: un tipo de violencia aceptado en la Baja Edad Media». Clio \& Crimen, 2008, vol. 5, pp. 39-71. 
García Marín, José María. «La legítima defensa hasta fines de la Edad Media. Notas para su estudio». Anuario de Historia del Derecho Español, 1987, vol. 57, pp. 413-438.

García Ulecia, Alberto. Los factores de diferenciación entre las personas en los fueros de la Extremadura castellano-aragonesa. Sevilla: Universidad de Sevilla, 1975.

Geertz, Clifford. La interpretación de las culturas. Barcelona: Gedisa, 2003.

GiL, Federico R. La institución matrimonial en la Hispania cristiana bajo-medieval (1215-1563). Salamanca: Universidad Pontificia de Salamanca, 1989.

Gilbert, Rafael. «Derecho penal». En Los fueros de Sepúlveda. Segovia: Diputación de Segovia, 1953, pp. 505-506.

Girard, René. La violencia y lo sagrado. Barcelona: Anagrama, 1972.

Groizard y Gómez de la Serna, Alejandro. El código penal de 1870, comentado y concordado. Tomo V. Salamanca: Esteban-Hermanos, Impresores, 1894.

Heusch, Carlos. «Femmes et violences dans les fueros castillans du Moyen Âge». Cahiers d'Études Hispaniques Médiévales, 2005, vol. 28, pp. 307-339.

Hinojosa, Eduardo. El elemento germánico en el derecho español. Madrid: Centro de Estudios Históricos, 1915.

Jiménez Cabanes, Pilar. «El deseo femenino a la luz de algunas composiciones literarias medievales». Lemir, 2005, vol. 9, s. p.

JimÉnez de Asúa, Luis. Tratado de derecho penal I. Buenos Aires: Editorial Losada, 1964.

LaCarra SAnZ, Eukene. «El peor enemigo, el enemigo en casa». Clio \& Crimen, 2008, vol. 5, pp. 228-266.

Lopes, Maria da Graça Videira. A sátira nos cancioneiros medievais galego-portugueses. Lisboa: Estampa, 1994. 2. ${ }^{\mathrm{a}} \mathrm{ed}$.

López OrTIZ, José. «El proceso en los reinos cristianos de nuestra Reconquista antes de la recepción romano-canónica». Anuario de Historia del Derecho Español, 1943, vol. 14, pp. 184-226.

López RasCh, Juan Cruz. «El monopolio de la violencia en el feudalismo como problema historiográfico", Anuario de la Facultad de Ciencias Humanas, 2012, vol. 10, pp. 1-16.

Machado Carillo, Mario J. El adulterio en el derecho penal. Pasado, presente y futuro. Madrid: Universidad Complutense de Madrid, 1977.

Madero, Marta. Manos violentas, palabras vedadas: la injuria en Castilla y León (siglos XIII-XV). Madrid: Taurus, 1992.

Mendoza Garrido, Juan Miguel. «Mujeres adúlteras en la Castilla medieval: delincuentes y víctimas». Clio \& Crimen, 2008, vol. 5, pp. 151-186.

Morín, Alejandro. «Matar a la adúltera: el homicidio legítimo en la legislación castellana medieval». Cahiers de Linguistique et de Civilisation Hispaniques Médiévales, 2001, vol. 24, pp. 353-380.

Morín, Alejandro. Pecado y delito en la Edad Media. Estudio de una relación a partir de la obra de Alfonso el Sabio. Córdoba: Ediciones del Copista, 2009.

Orlandis Rovira, José. "Las consecuencias del delito en el derecho de la Alta Edad Media». Anuario de Historia del Derecho Español, 1947, vol. 18, pp. 61-166.

Ors, Álvaro d'. Estudios visigóticos II. Roma-Madrid: Consejo Superior de Investigaciones Científicas, 1960.

Osaba García, Esperanza. El adulterio uxorio en la Lex Visigothorum. Madrid: Marcial Pons, 1997.

Pereda, Julián. «El uxoricidio». Anuario de Derecho Penal y Ciencias Penales, 1951, vol. 4, n.o 3, pp. 518-545.

Pérez Martín, Antonio. «Fuentes romanas en las Partidas». Glossae, 1992, vol. 4, pp. 215-246.

Pérez Martín, Antonio. «La protección del honor y de la fama en el derecho histórico español». Anales de Derecho, 1991, vol. XI, pp. 117-156. 
LA VIOLENCIA DEL CORNUDO COMO REACCIÓN ANTE EL DELITO DE ADULTERIO.

Pitt-Rivers, Julien. «Honor y categoría social». En Peristiany, John G. El concepto del honor en la sociedad mediterránea. Barcelona: Labor, 1968.

Pitt-Rivers, Julien. «La enfermedad del honor». En Gautheron, Marie (ed.). El honor. Imagen de sí mismo o don de sí, un ideal equivoco. Madrid: Cátedra, 1992.

Pitt-Rivers, Julien. Antropología del honor o politica de los sexos. La influencia del honor y el sexo en la vida de los pueblos mediterráneos. Barcelona: Editorial Crítica, 1979.

Rodríguez Marín, José Luis. "Los efectos sociales del adulterio femenino». En Trillo San José, Carmen (coord.). Mujeres, familia y linaje en la Edad Media. Granada: Universidad de Granada, 2004, pp. 137-190.

Rodríguez Ortiz, Victoria. Historia de la violación. Su regulación jurídica hasta fines de la Edad Media. Madrid: Consejería de Educación y Cultura de la Comunidad de Madrid, 1997.

Serra Ruiz, Rafael. Honor, honra e injuria en el derecho medieval español. Murcia: Sucesores de Nogués, 1969.

Solórzano Telechea, Jesús Ángel. «Justicia y ejercicio del poder: la infamia y los delitos de lujuria en la cultura legal de la Castilla medieval». Cuadernos de Historia del Derecho, 2005, vol. 12, pp. 313-353.

Tomás y VAlIENTE, Francisco. El derecho penal de la monarquía absoluta: (siglos XVI, XVII y XVIII). Madrid: Tecnos, 1969.

Van der Leeuw, Gerardus. La fenomenología de la religión. México-Buenos Aires: Fondo de Cultura Económica, 1964.

Zeumer, Karl. Historia de la Legislación Visigoda. Barcelona: Universidad de Barcelona, 1944. 